\title{
Evaporative dense water formation and cross-shelf exchange over the northwest Australian inner shelf
}

\author{
R. Kipp Shearman ${ }^{1}$ and Kenneth H. Brink ${ }^{2}$ \\ Received 21 October 2009; revised 8 January 2010; accepted 2 February 2010; published 29 June 2010.
}

[1] High-resolution surveys of oceanographic and atmospheric conditions made during the winter over the inner shelf off northwest Australia are used to examine the coastal ocean response to large outgoing heat and freshwater fluxes. Relatively cool, low-humidity air blows off the Australian continent out over the tropical continental shelf, resulting in a large mean latent heat flux $\left(-177 \mathrm{~W} \mathrm{~m}^{-2}\right)$ that overwhelms insolation and, along with the outgoing long-wave radiation, results in substantial net cooling $\left(-105 \mathrm{~W} \mathrm{~m}^{-2}\right)$ and evaporative freshwater flux $\left(0.6 \mathrm{~cm} \mathrm{~d}^{-1}\right)$. The inner shelf is characterized by increasingly cool, salty, and dense waters onshore, with a strong front near the $25 \mathrm{~m}$ isobath. The front is evident in satellite sea surface temperature (SST) imagery along the majority of the northwest Australian shelf, exhibiting a complex filamentary and eddy structure. Cross-shelf buoyancy fluxes estimated from the mean, two-dimensional heat and salt budgets are comparable to parameterizations of cross-shelf eddy driven fluxes; however, the same fluxes can be achieved by cross-shelf transports in the bottom boundary layer of about $0.5 \mathrm{~m}^{2} \mathrm{~s}^{-1}$ (and an overlying return flow).

Citation: Shearman, R. K., and K. H. Brink (2010), Evaporative dense water formation and cross-shelf exchange over the northwest Australian inner shelf, J. Geophys. Res., 115, C06027, doi:10.1029/2009JC005931.

\section{Introduction}

[2] The northwest Australian shelf is the headwaters of the Leeuwin Current (hereafter LC), unique among eastern boundary currents, because it flows poleward against the prevailing winds, driven instead by an along-shelf pressure gradient [Godfrey and Ridgway, 1985]. The LC connects with the South Australian Current at Cape Leeuwin, creating a greater boundary flow over $5000 \mathrm{~km}$ long [Ridgway and Condie, 2004]. Off northwest Australia, the LC manifests itself at the shelf break as an along-shelf southwestward flow of about $0.20 \mathrm{~m} \mathrm{~s}^{-1}$, approximately $400 \mathrm{~m}$ deep and $200 \mathrm{~km}$ wide, resulting in a substantial transport of about $4 \mathrm{~Sv}$ [Holloway and Nye, 1985; Holloway, 1995]. An interesting feature of the northwest Australian shelf (firmly situated in the tropics) is the seasonal appearance of cool, salty water inshore during the winter, when the wind field is dominated by the southeasterly trade winds [Holloway and Nye, 1985]. The cool, salty water was originally believed to be the product of upwelling, but the wind forcing was insufficient to achieve the observed cooling [Wyrtki, 1962] and the formation mechanism was presumed to be evaporative cooling [Gentilli, 1972; Holloway, 1995; Godfrey and Mansbridge, 2000]. Another defining characteristic of the northwest Australian shelf is the large semidiurnal barotropic tide. The $M_{2}$ tidal

\footnotetext{
${ }^{1}$ College of Oceanic and Atmospheric Sciences, Oregon State University, Corvallis, Oregon, USA.

${ }^{2}$ Department of Physical Oceanography, Woods Hole Oceanographic Institution, Woods Hole, Massachusetts, USA.

Copyright 2010 by the American Geophysical Union. 0148-0227/10/2009JC005931
}

height amplitude increases from $0.9 \mathrm{~m}$ at the shelf break to about $2.0 \mathrm{~m}$ at the coast between Port Hedland and Broome [Figure 6, Holloway, 1983b], and $M_{2}$ tidal currents in $32 \mathrm{~m}$ water depth near Dampier (to the southwest of Port Hedland) have an amplitude of about $0.30 \mathrm{~m} \mathrm{~s}^{-1}$ along shore and $0.10 \mathrm{~m}$ $\mathrm{s}^{-1}$ cross shelf [Table 4, Holloway, 1983b]. Semidiurnal internal tides are also large on the northwest Australia shelf and are dominated by a first baroclinic mode vertical structure with currents reaching $0.20 \mathrm{~m} \mathrm{~s}^{-1}$ [Holloway, 1983a, 1994; Holloway et al., 2001]; however, internal tidal activity is usually at a minimum during the winter months [Holloway et al., 2001].

[3] Dense water formation in the coastal ocean, by cooling, evaporation, or brine rejection during freezing, is a globally important process, impacting thermohaline circulation and providing an efficient mechanism of cross-shelf exchange of material properties [Condie, 1995; Huthnance, 1995]. The response of the coastal ocean to large outgoing surface buoyancy fluxes and the export of dense water across the shelf has been the subject of modeling [Gawarkiewicz and Chapman, 1995; Chapman and Gawarkiewicz, 1997; Spall and Chapman, 1998; Pringle, 2001] and laboratory studies [Whitehead et al., 1990; Cenedese et al., 2004]. A particularly interesting result from the modeling and laboratory studies is the importance of three-dimensional eddies and turbulent lateral mixing in driving cross-shelf transport, as opposed to cross-shelf transport in the bottom boundary layer, driven by a combination of gravitation, friction, and rotation. Unfortunately, there are few observations resolving the complex three-dimensional structure of active dense water formation and offshore transport in the coastal ocean, because events are 

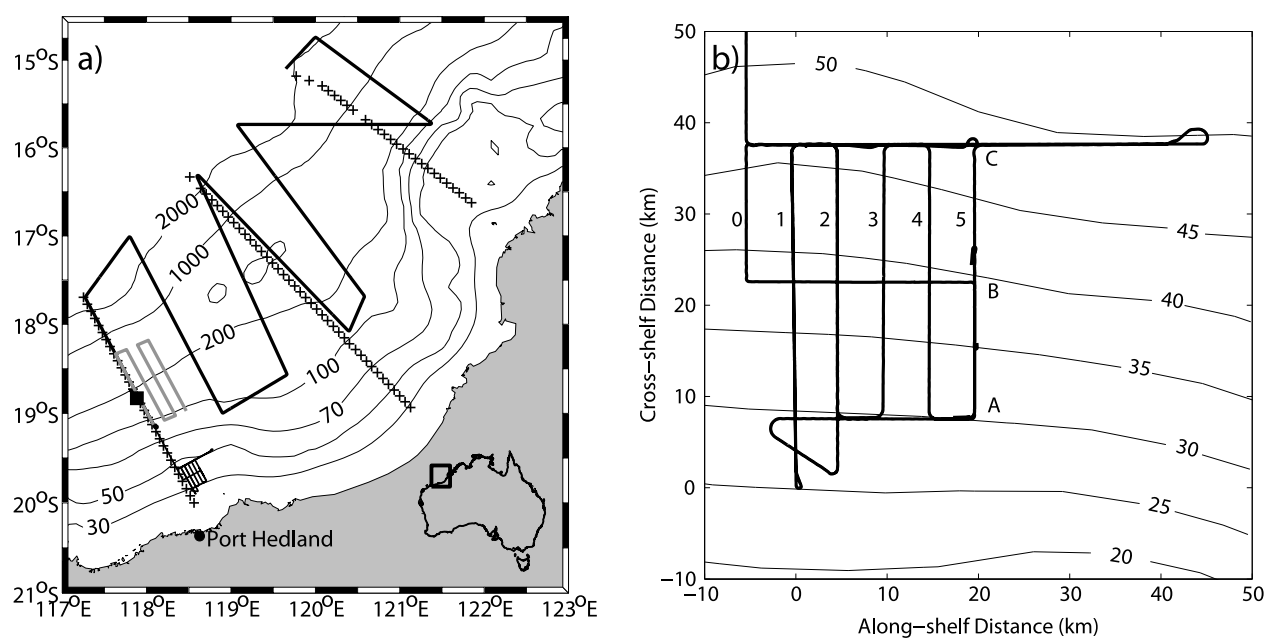

Figure 1. (a) Map showing the observations made along the northwest Australian shelf (inset) during the June/July experiment: the MiniBat survey (thin black line), the large-scale (thick black line) and repeat radiator (gray line) SeaSoar surveys, CTD locations (crosses) and $150 \mathrm{~m}$ isobath mooring site (black square). (b) The MiniBat survey in the along-/cross-shelf $(x, y)$ coordinate system. Cross-shelf sections are numbered $(0-5)$, and along-shelf sections are labeled with letters $(\mathrm{A}-\mathrm{C})$. Bathymetry contours are shown in meters.

highly variable in space and time [Huthnance, 1995], and the common high-latitude regions [e.g., Aagaard et al., 1981] of dense water formation are formidable environments for instrumentation.

[4] From 18 June to 17 July 2003, moored and ship-based observations of hydrography, currents, optical properties, and atmospheric conditions were made over the northwest Australian continental shelf and slope (Figure 1a) with the goal of understanding the interaction between the shelf circulation and mesoscale variability in the shelf break LC. Brink et al. [2007] examined the spatial variability in the LC at the shelf break and found a rich submesoscale $(10 \mathrm{~km})$ eddy field. Brink and Shearman [2006] examined shelf/open ocean exchange via the bottom boundary layer and found pronounced tongues of dense, high-salinity shelf water ejected at the shelf break during a reversal in the normally southwestward flowing LC. Dense water formation is primarily deemed a high-latitude process, but these observations suggest that the tropical northwest Australian shelf is forming and exporting relatively dense water to the open ocean. The observations, thus, provide an opportunity to examine in some detail dense water formation, cross-shelf transport, and the relative role of eddies and the bottom boundary layer.

[5] The objectives of this paper are to describe the physical characteristics of the inner shelf off northwest Australia under winter time conditions, when the coastal ocean experiences strong evaporative cooling; to examine the response of the coastal ocean to strong outgoing heat and freshwater fluxes; and to evaluate the resulting connections between the inner and outer shelf via lateral fluxes caused by eddies and the bottom boundary layer. The remainder of the paper is organized as follows: section 2 summarizes the observations made during the June/July 2003 Northwest Australian Shelf Dynamics Experiment; section 3 describes the observed atmospheric conditions along the northwest Australian shelf; section 4 recounts the observed oceanic response to large surface buoyancy loss; section 5 discusses the important physical processes affecting the structure and evolution of the temperature, salinity, and density fields; and section 6 offers our conclusions.

\section{Observations}

[6] In addition to the moored and ship-based profiling, acoustic Doppler current profiler (ADCP), and towed, undulating SeaSoar observations described by Brink and Shearman [2006] and Brink et al. [2007], we utilize the ship-based meteorological observations and measurements from a smaller towed, undulating instrument platform called a MiniBat [e.g., Dale et al., 2008]. Sampling was centered on surveys of progressively finer resolution and onshore position (Figure 1a) off the northwest shelf of Australia. Unfortunately, during the inner shelf surveys, technical difficulties with the shipboard ADCP resulted in no usable direct velocity measurements.

[7] The meteorological observations onboard the $\mathrm{R} / \mathrm{V}$ Melville included air temperature, relative humidity, barometric pressure, precipitation, downward short-wave and long-wave radiation, and wind speed and direction from a mast on the bow of the ship approximately $16.8 \mathrm{~m}$ above the mean water line and sea surface temperature (SST) and conductivity from the bow seawater intake. All measurements were made at $30 \mathrm{~s}$ intervals and subsequently averaged to $1 \mathrm{~h}$ intervals for the entirety of the cruise (18 June to 17 July 2003).

[8] The MiniBat platform was used to perform an inner shelf (20-50 m depth range) survey from 9-13 July 2003 (Figure 1b). The MiniBat towed, undulating instrument platform was sampled from the surface to $2-7 \mathrm{~m}$ above the bottom with a $50 \mathrm{~m}$ maximum depth and was towed at 3$5 \mathrm{~km}$, completing an undulation cycle in less than $200 \mathrm{~m}$ along-track distance. We performed an initial $80 \mathrm{~km}$ long cross-shelf section from the shelf break SeaSoar survey region to the $50 \mathrm{~m}$ isobath, staying far above the bottom. Then we performed a $45 \mathrm{~km}$ long along-shelf section roughly paralleling the $45 \mathrm{~m}$ isobath, decreasing the distance to the 


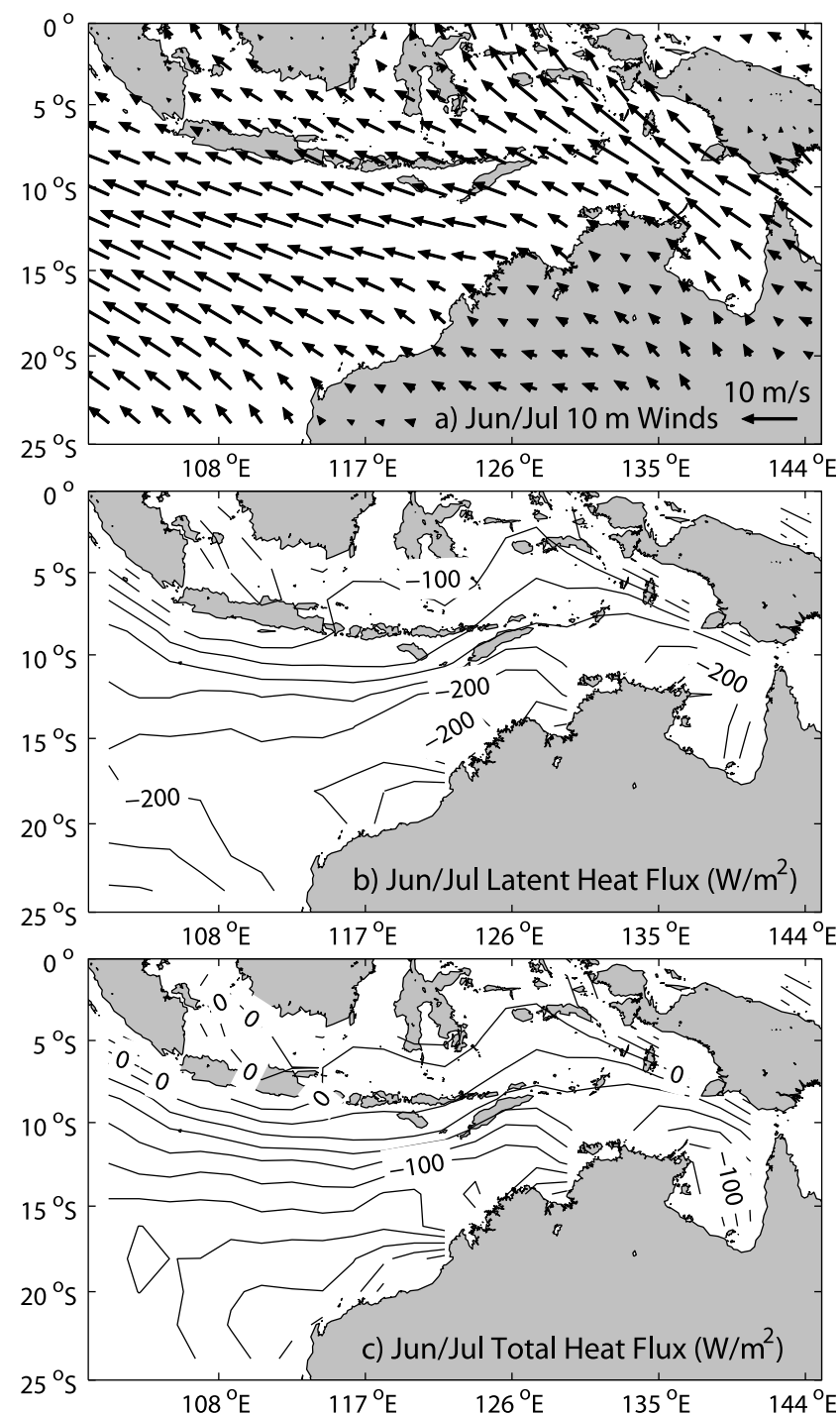

Figure 2. Climatological average June/July: (a) $10 \mathrm{~m}$ winds, (b) latent heat flux, and (c) total heat flux from National Centers for Environmental Prediction (NCEP) reanalysis. During Austral winter, winds bring relatively cool dry air off the continent and out over the tropical ocean, resulting in large latent heat fluxes and net cooling.

bottom to $2-7 \mathrm{~m}$. Over the next 3 days, we conducted eight cross-shelf sections (spanning the $25-45 \mathrm{~m}$ isobaths, approximately $40 \mathrm{~km}$ in distance, lines 1-5 in Figure 1b) and five approximately $20 \mathrm{~km}$ long along-shelf sections (following roughly the 25,35 , and $45 \mathrm{~m}$ isobaths, lines $\mathrm{A}, \mathrm{B}$, and $\mathrm{C}$ in Figure 1b). Little is known about decorrelation time scales on the northwest Australian shelf; however, individual lines are completed in 3-8 $\mathrm{h}$ and are treated as synoptic realizations. Semidiurnal tides are large on the NW Australian shelf [Holloway, 1983b; Holloway et al., 2001], both barotropic and internal tides, and are a substantial source of noise compared to the subtidal fields of interest.

[9] The MiniBat was equipped with a pumped SeaBird 25 CTD (conductivity-temperature-depth) sensor and WETLabs fluorometer and transmissometer, all sampling at $8 \mathrm{~Hz}$. The conductivity and temperature sensors were calibrated before and after the cruise, and the data were adjusted for pumping system and thermal lags [Lueck, 1990]. The $8 \mathrm{~Hz}$ data were averaged to $1 \mathrm{~Hz}$, and quality was controlled by removing single-point spikes and out-of-range data. The $1 \mathrm{~Hz}$ qualitycontrolled observations are geolocated in a two-step process, because the SBE25 on the MiniBat did not directly integrate GPS positions. First, the ship's GPS position data are temporally merged with the measurements from a second pressure sensor on the MiniBat at $1 \mathrm{~s}$ intervals. Second, using $3 \mathrm{~h}$ segments of $1 \mathrm{~s}$ data, the CTD and GPS data are merged by computing the lagged correlation between the two pressure sensors and shifting the CTD observations accordingly. The GPS data stream also contains bottom depth from the ship's depth finder.

\subsection{Gridding}

[10] For some aspects of the following analysis, we grid and smooth the $1 \mathrm{~Hz}$ quality-controlled, geolocated MiniBat observations. The along-shelf $(x)$ and cross-shelf $(y)$ coordinate system (Figure 1b) we choose has the $x$ axis oriented $61.5^{\circ} \mathrm{T}, y=0$ is approximately the position of the $25 \mathrm{~m}$ isobath, and line 0 coincides with the initial cross-shelf CTD section [Brink and Shearman, 2006]. We use an iterative Barnes algorithm [Daley, 1993] to create gridded and smoothed versions of the eight cross-shelf sections. The Barnes gridding uses Gaussian weighting and starts with $10 \mathrm{~km}$ horizontal and full water depth vertical scales, reducing to approximately $2 \mathrm{~km}$ and $2 \mathrm{~m}$ scales over 10 iterations.

\section{Atmospheric Forcing}

[11] During austral winter, atmospheric conditions over the northwest Australian shelf are strongly influenced by the southeast trade winds blowing off of the continent (Figure 2a). Northwest Australia is largely a desert, and during the wintertime, this leads to relatively cool, dry air moving out over the warm tropical ocean, resulting in sizable latent heat fluxes (about $-200 \mathrm{~W} \mathrm{~m}^{-2}$ ) in the climatological average (Figure 2b). Despite the strong insolation in the tropics, the total heat flux is acting to cool the coastal ocean (Figure 2c), and this is most likely the cause of previously observed cold water near shore.

[12] During 18 June through 17 July, the ship's meteorological observations appear to support the climatological picture. Air temperature was almost always cooler than sea surface temperature with an average difference of $-1.5^{\circ} \mathrm{C}$ and an extended period (27 June to 5 July) when the difference was larger than $-2.0^{\circ} \mathrm{C}$ (Figure 3a). Relative humidity ranged from $20 \%$ to $90 \%$ with an average of $60 \%$, and during the extended period of relatively cool air temperatures, relative humidity dropped from a high of $93 \%$ to consistently near $40 \%$ (Figure 3b). Wind speeds (corrected for ship's speed) ranged from 0 to $13 \mathrm{~m} \mathrm{~s}^{-1}$ and were typically to the northwest (Figure 3c) consistent with the climatological winds. There was an identifiable diurnal cycle in the winds, transitioning from onshore during the day to offshore at night, and a weak diurnal cycle in the air temperature and relative humidity. There was very little spatial variability in the meteorological fields, except very close to shore $(<30 \mathrm{~m}$ depth), where sea surface temperatures were substantially lower than offshore values. 

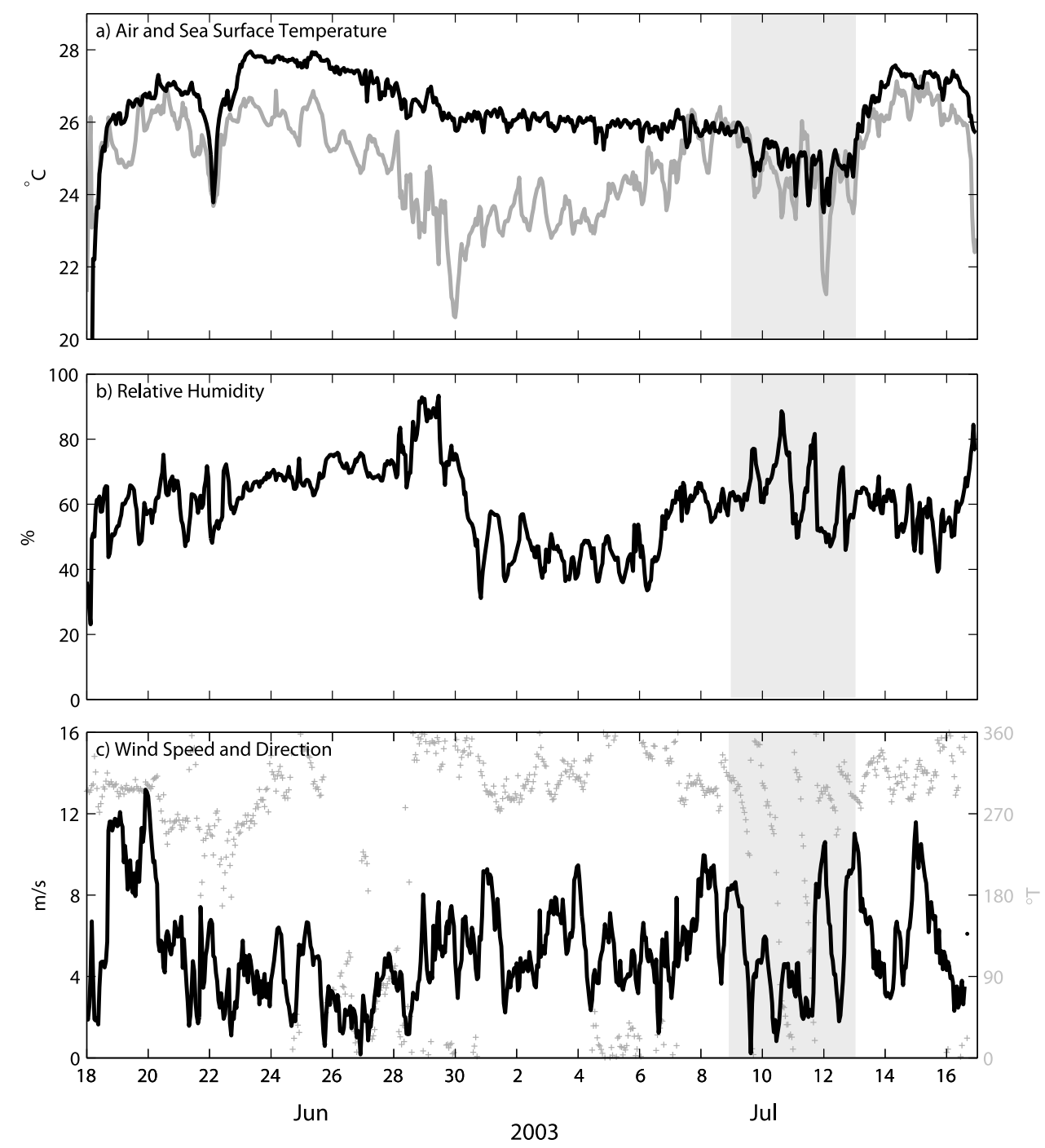

Figure 3. Ship-based observations of (a) air (gray line) and sea surface (black line) temperatures, (b) relative humidity, and (c) absolute wind speed (black line) and direction (gray circles). The period of the inner shelf MiniBat survey is shaded gray.

[13] Using the ship's meteorological observations, we compute bulk estimates [Fairall et al., 1996] of the latent, sensible, net long-wave and net short-wave surface heat fluxes and cumulative evaporation minus precipitation freshwater export. The incoming short-wave radiation is expectedly quite large; the net long-wave radiation is fairly constant, on average $-90 \mathrm{~W} \mathrm{~m}^{-2}$; and the sensible heat flux is weak (Figure 4a). The latent heat flux is typically the largest heat flux out of the ocean with an average of $-177 \mathrm{~W} \mathrm{~m}^{-2}$ and several events exceeding $-400 \mathrm{~W} \mathrm{~m}^{-2}$ (Figure $4 \mathrm{a}$ ). The total surface heat flux ranged from -604 to $531 \mathrm{~W} \mathrm{~m}^{-2}$ with a mean of $-105 \mathrm{~W} \mathrm{~m}^{-2}$ (Figure $4 \mathrm{~b}$ ). The largest outgoing heat fluxes occurred at night during the period of large air-sea temperature difference and low relative humidity ( 30 June and 3 July). Over the period of the cruise, the rate of freshwater loss due to evaporation was nearly constant at $0.6 \mathrm{~cm} \mathrm{~d}^{-1}$ with peak values of $1.5 \mathrm{~cm} \mathrm{~d}^{-1}$ and only a few precipitation events. The cumulative freshwater export over the duration of the cruise was $17 \mathrm{~cm}$ (Figure $4 \mathrm{~b}$ ). There was no discernable spatial structure associated with any of the surface flux fields.
[14] We compute the average surface buoyancy flux $(B)$ by estimating the contributions from the mean surface heat flux $(Q)$ and freshwater flux $(E)$. Following Pringle [2001], the buoyancy flux attributable to surface heat flux is estimated as

$$
B_{\mathrm{T}}=-\frac{g \alpha Q}{\rho_{\mathrm{o}} c_{\mathrm{p}}},
$$

where $g$ is the gravitation acceleration $\left(9.8 \mathrm{~m} \mathrm{~s}^{-2}\right), \alpha$ is the thermal expansion coefficient $\left(-0.31 \mathrm{~K} \mathrm{~kg}^{-1} \mathrm{~m}^{3}\right)$ and is a strong function of temperature (the mean surface temperature is about $\left.26{ }^{\circ} \mathrm{C}\right), \rho_{\mathrm{o}}$ is average density $\left(1025 \mathrm{~kg} \mathrm{~m}^{-3}\right)$, and $c_{\mathrm{p}}$ is the specific heat of seawater $\left(4000 \mathrm{~J} \mathrm{~kg}^{-1} \mathrm{~K}\right)$. The contribution to the surface buoyancy flux due to the evaporative freshwater loss and precipitation gain is estimated as

$$
B_{\mathrm{S}}=g \beta E S_{0},
$$

where $\beta$ is the haline contraction coefficient $\left(0.756 \mathrm{~kg}^{-1} \mathrm{~m}^{3}\right)$ and $S_{\mathrm{o}}$ is a reference salinity (35). The average $B_{\mathrm{T}}=$ $-7.7 \times 10^{-8} \mathrm{~m}^{2} \mathrm{~s}^{-3}$ and the average $B_{\mathrm{S}}=-1.7 \times 10^{-8} \mathrm{~m}^{2} \mathrm{~s}^{-3}$, 

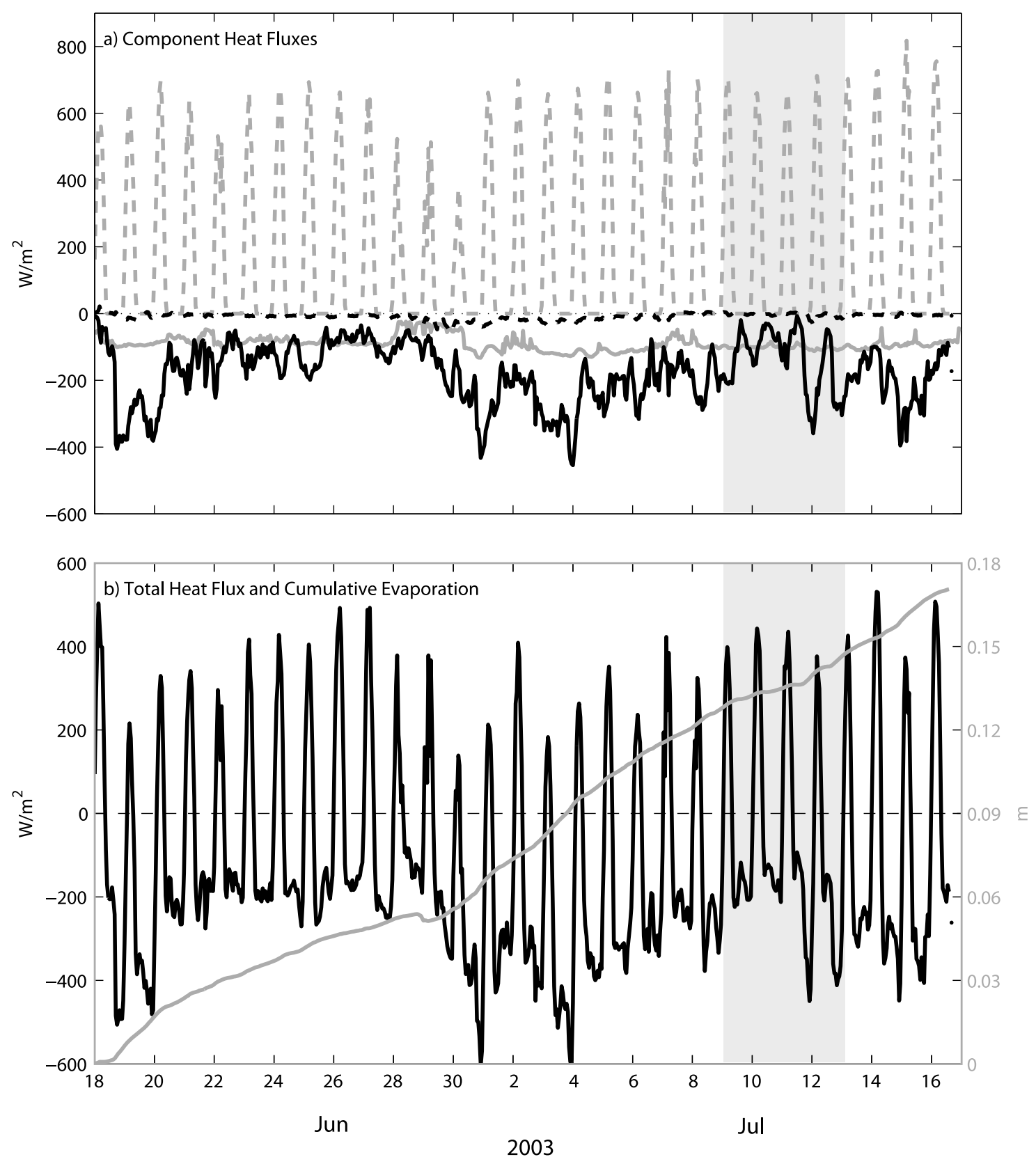

Figure 4. (a) Short-wave (dashed gray line), long-wave (gray line), latent (black line), and sensible (dashed black line) heat fluxes estimated from meteorological observations (positive indicates heat into the ocean). (b) Total heat flux (black line) and cumulative freshwater flux (gray line).

yielding a total average buoyancy flux of $B=-9.4 \times$ $10^{-8} \mathrm{~m}^{2} \mathrm{~s}^{-3}$ (negative values indicate a flux out of the ocean). The average buoyancy flux for the tropical northwest Australian shelf is comparable to winter time fluxes over the middle Atlantic bight [Mountain et al., 1996] and about one third of the seasonally averaged buoyancy flux in the western Arctic, where surface fluxes are mainly through coastal polynyas [Cavalieri and Martin, 1994].

\section{Oceanic Response}

[15] Surface ocean waters become cooler, saltier, and denser in the onshore direction. The temperature-salinity $(T-S)$ diagram (Figure 5) for shelf water, from the $20 \mathrm{~m}$ isobath to the shelf break at the $200 \mathrm{~m}$ isobath, has two main branches. The first is a low-salinity arm that spans a large range of temperature. This is the relatively fresh Leeu 4 win Current core [Holloway, 1995; Brink et al., 2007] that appears in the permanent pycnocline at the shelf break (150-250 m water depth). The second is a relatively warm arm that becomes progressively cooler, saltier, and denser, reaching end values of $T=22^{\circ} \mathrm{C}, S=36$, and $\sigma_{\theta}=24$ at the CTD cast from $20 \mathrm{~m}$ water depth. This arm is composed of water entirely above $100 \mathrm{~m}$ depth and forms a nearly linear connection from the cool, salty inner shelf waters to the climatological average June $T-S$ values of $T=26.8^{\circ} \mathrm{C}$ and $S=34.5$ (Figure 5, 


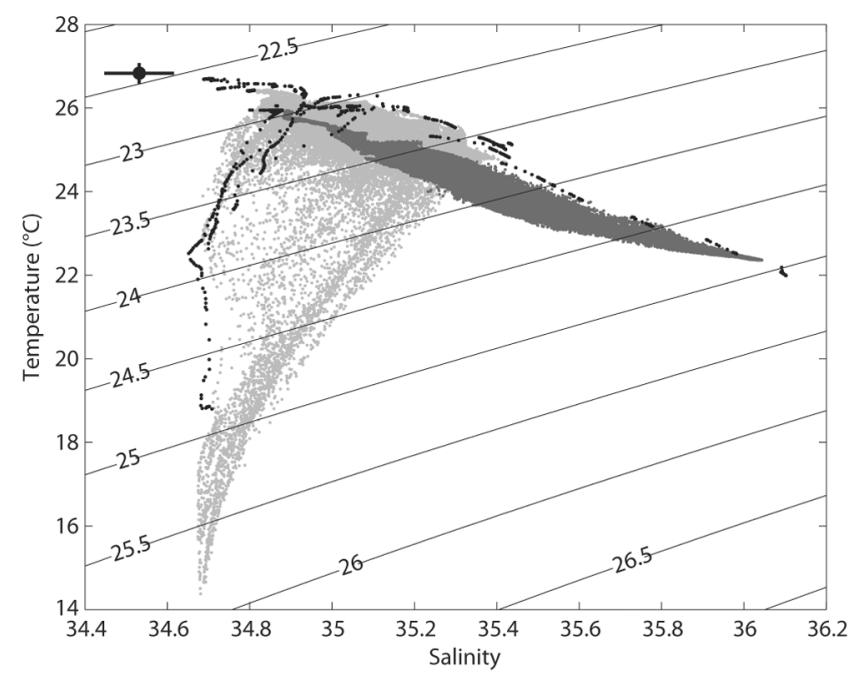

Figure 5. Temperature-salinity diagram for observations inshore of the $200 \mathrm{~m}$ isobath along the cross-shelf section off Port Hedland. Observations are from the profiling CTD (black), SeaSoar (light gray), and MiniBat (dark gray). In addition, the climatological average June $T-S$ value (black circle $) \pm$ a standard deviation for the offshore $\left(117^{\circ} \mathrm{E}, 17^{\circ} \mathrm{S}\right)$ surface layer $(<50 \mathrm{~m})$ is shown. Contours are of potential density anomaly.

large black circle). The climatological values are estimated from the World Ocean Atlas [Antonov et al., 2006; Locarnini et al., 2006] for the offshore $\left(17^{\circ} \mathrm{E}, 17^{\circ} \mathrm{S}\right)$ surface mixed layer. There is a significant change in the fresh Leeuwin Current core branch of the $T-S$ diagram between the time of the CTD observations (Figure 5, black circles) and the SeaSoar observations (Figure 5, light gray circles) approximately 10 days later: the freshest values associated with the Leeuwin Current core shift to higher densities and are replaced by saltier water that connects along a mixing line to the onshore surface water branch of the $T-S$ diagram. This period corresponds to an evacuation of shelf water through the bottom boundary layer during a Leeuwin Current flow reversal, which formed long tongues of high-salinity shelf water extending out into the deep ocean along the pycnocline [Brink and Shearman, 2006]. The waters over the shelf are thus the product of three basic water types: the warm, fresh offshore surface mixed layer; the cool, fresh Leeuwin Current core waters in the pycnocline at the shelf break; and the inner shelf waters that become increasing cool, salty, and dense onshore.

\subsection{Cross-Shelf Structure}

[16] Using two serial occupations of line 1 with the MiniBat, collected over a $12 \mathrm{~h}$ period on 11 July 2003, we compute the average cross-shelf section (to minimize tidal aliasing) for temperature, salinity, and density (Figure 6). Shelf waters become progressively cooler, saltier, and denser onshore; however, there is a sharp front $(<5 \mathrm{~km}$ wide) that outcrops the surface at about the $25 \mathrm{~m}$ isobath. The front is steeply sloped $\left(-3 \times 10^{-3}\right)$ from 0 to $8 \mathrm{~km}$ offshore (from the $25 \mathrm{~m}$ isobath) where it flattens out, merging with the pycnocline and roughly following the bottom slope $\left(-4 \times 10^{-4}\right)$. Density gradients across the front are about $-2 \times 10^{-4} \mathrm{~kg} \mathrm{~m}^{-4}$.
There is a slightly weaker secondary front farther offshore at $x=12 \mathrm{~km}$, with density gradients of about $-0.5 \times 10^{-4} \mathrm{~kg} \mathrm{~m}^{-4}$, separated from the primary front by a region of less stratified water (Figure 6). The secondary front outcrops the surface at about the $30 \mathrm{~m}$ isobath (about the place where the primary front joins the pycnocline) and has a steep isopycnal slope nearly identical to the primary front from $x=9-16 \mathrm{~km}$ offshore, where it also joins the pycnocline and approximately follows the bottom slope.

[17] The pair of fronts separate relatively well-mixed, cool, salty inner shelf waters from midshelf waters, which are characterized by two distinct layers separated by a strong pycnocline (peak values of $N^{2}=1 \times 10^{-3} \mathrm{~s}^{-2}$ ). The upper layer is relatively warm and fresh and shares $T-S$ characteristics with the offshore surface layer, and the lower layer is cool and salty and shares characteristics with the inner shelf (Figure 5). Both layers become cooler and saltier onshore. The inshore region connects with the rest of the shelf through the bottom boundary layer. Although we have no useful direct velocity measurements for this region, we can infer the crossshelf movement of water below the pycnocline, because the only source for cool, salty water is the inner shelf.

[18] Surface and bottom boundary layer thicknesses are estimated from the MiniBat observations using a density threshold of $0.03 \mathrm{~kg} \mathrm{~m}^{-3}$ [Lentz and Trowbridge, 1991; Lentz, 1992], and average thicknesses are computed for $4 \mathrm{~km}$ bins in the cross-shelf direction. The average bottom boundary layer thickness, nearest shore in approximately $25 \mathrm{~m}$ water depth, is about $11 \mathrm{~m}$, and the average surface boundary layer thickness is about $9 \mathrm{~m}$ (Figure 7a). Average bottom boundary layer thickness reaches a broad minimum just offshore of the front and then increases persistently in the offshore direction to a maximum of $20 \mathrm{~m}$. Surface mixed layer thickness does not consistently increase in the offshore direction and has a maximum of about $18 \mathrm{~m}$. Temperature in the surface and bottom mixed layers increases in the offshore direction (Figure $7 b$ ). In the surface layer, temperature increases rapidly from 0 to $20 \mathrm{~km}$ and then is nearly constant, while in the bottom layer, temperature increases nearly uniformly in the offshore direction from 0 to $40 \mathrm{~km}$. Salinity in both layers decreases offshore, and the surface/bottom structure difference is identical to temperature (Figure $7 \mathrm{c}$ ). Inferring the offshore movement in the bottom boundary layer, the increase in bottom boundary layer thickness and temperature and decrease in salinity are consistent with entrainment of the overlying surface waters.

[19] We estimate along-shelf geostrophic velocities (Figure 8) from the average cross-shelf section of density (Figure 6c), gridded and smoothed over $2 \mathrm{~km}$ horizontal and $2 \mathrm{~m}$ vertical scales, and referenced to a value of zero at the bottom $(z=-H)$. The along-shelf geostrophic flow is surface intensified with peak currents of $0.48 \mathrm{~m} \mathrm{~s}^{-1}$, heading equatorward, and are situated just offshore of the outcropping isopycnals in the primary front. There is also a local maximum of $0.25 \mathrm{~m} \mathrm{~s}^{-1}$ just offshore of the outcrop of the secondary front.

\subsection{Lateral Variability}

[20] Satellite sea surface temperature images of the NW Australian shelf, such as the image from 11 July 2003 (Figure 9), reveal that the basic cross-shelf temperature structure (i.e., cool water onshore) exists over more than $700 \mathrm{~km}$ 

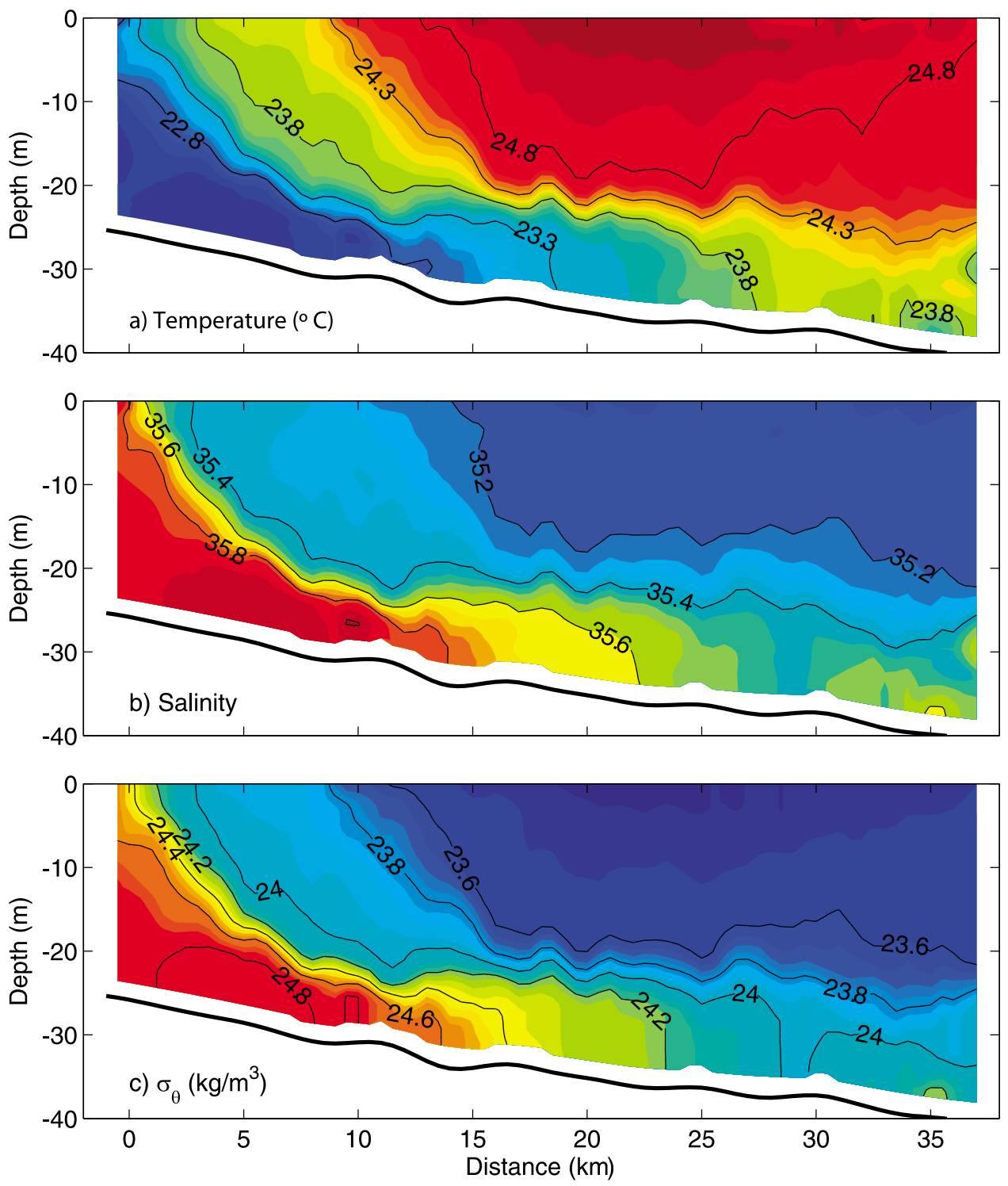

Figure 6. Average cross-shelf sections of (a) temperature, (b) salinity, and (c) potential density, computed from two occupations of line 1 with the MiniBat over a $12 \mathrm{~h}$ period on 11 July 2003.

along shelf. The conditions could easily be mistaken for coastal upwelling, and indeed historically they were, but the prevailing winds are not upwelling favorable (Figures $2 \mathrm{a}$ and $3 \mathrm{c}$ ). Furthering the comparison with upwelling regions like the U.S. West Coast [e.g., Strub et al., 1991], however, is the presence of a complex field of filamentary and eddylike structures (Figure 9). Over the NW Australian shelf, there are filaments as long as $100 \mathrm{~km}$, extending from inshore of the 50-m isobath to offshore of the 100-m isobath (approximately the shelf break), and isolated lenses of relatively cool water ranging from 25 to $50 \mathrm{~km}$ in diameter.

[21] The presence, character, and influence of eddies on the inner shelf is an important issue. Here, we characterize the eddy scale variability over the inner shelf, using along-shelf and cross-shelf correlation structure functions. We then compare the dominant length scales with theoretical scales to infer the related dynamics of the eddies. Specifically, we compute spatially lagged $(0-20 \mathrm{~km})$ autocorrelations for potential density (Figure 10). To compute the cross-shelf correlation structure, we use the MiniBat observations at $10 \mathrm{~m}$ depth $( \pm 1 \mathrm{~m})$ from five individual cross-shelf sections at fixed along-shelf positions $(x=0,5$, and $10 \mathrm{~km})$. The sections range from 30 to $37 \mathrm{~km}$ long. We block average the data onto a $500 \mathrm{~m}$ grid (recall the resolution of the undulating MiniBat is less than $200 \mathrm{~m}$ ) and compute the spatially lagged autocorrelation for each section. Finally, we average the five lagged autocorrelation estimates to compute the representative cross-shelf correlation structure. We calculate spatial correlation structures for both the raw potential density and the residual density field [e.g., Shearman et al., 1999] with the time-independent, spatially varying mean removed at $10 \mathrm{~m}$ depth,

$$
\sigma_{\theta}^{\mathrm{res}}=\sigma_{\theta}^{\mathrm{raw}}-\bar{\sigma}_{\theta}
$$


a) Boundary layer thickness

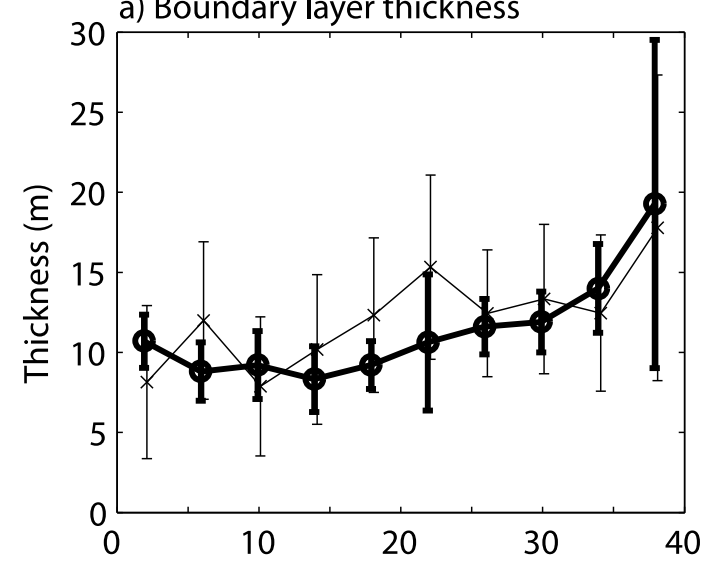

b) Temperature
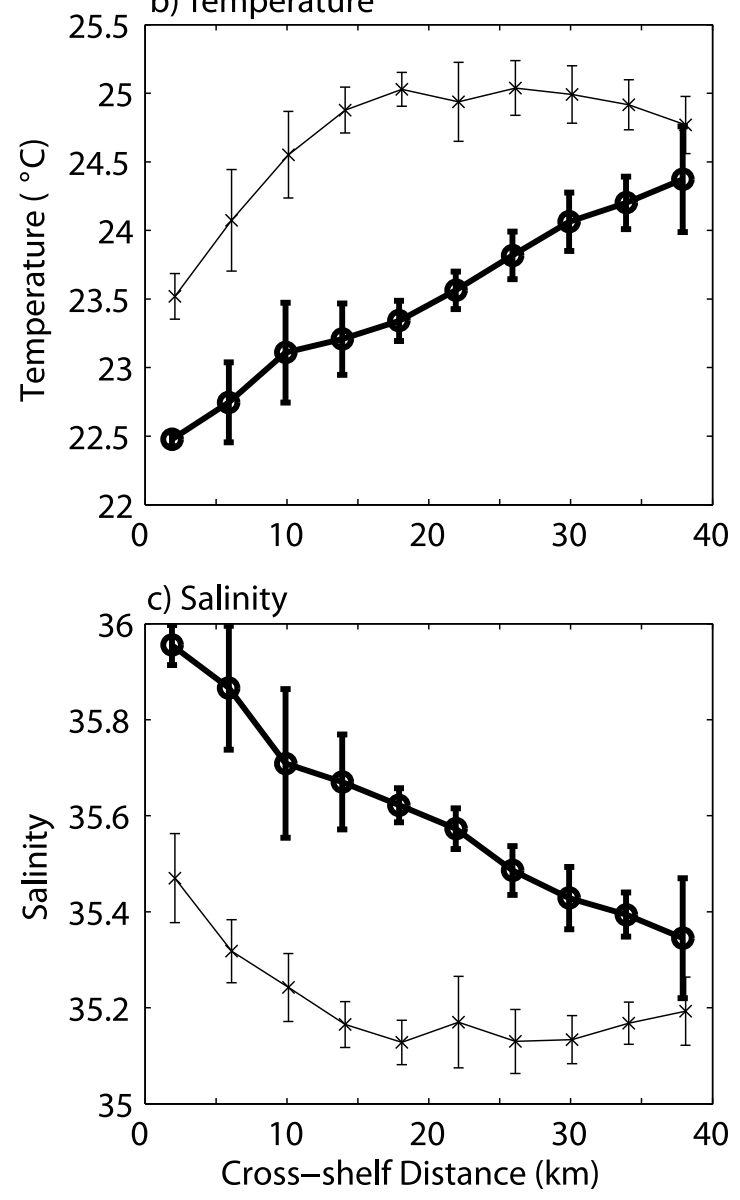

Figure 7. (a) Average surface (thin line, crosses) and bottom (thick line, circles) boundary layer thickness versus crossshelf position ( $4 \mathrm{~km}$ bins), estimated from MiniBat observations of potential density using a threshold of $0.03 \mathrm{~kg} \mathrm{~m}^{-3}$ with standard deviations and average (b) temperature and (c) salinity in the surface (thin line, crosses) and bottom (thick line, circles) boundary layers with standard deviations.

where

$$
\bar{\sigma}_{\theta}=A_{1} x^{2}+A_{2} x y+A_{3} y^{2}+A_{4} x+A_{5} y+A_{6},
$$

and the coefficients $A_{1}-A_{6}$ are estimated by linear regression to all of the raw observations. We repeat the process to compute the along-shelf correlation structure, using five individual along-self sections at fixed cross-shelf positions, centered approximately on the 25,35 , and $45 \mathrm{~m}$ isobaths. The along-shelf sections range from 15 to $45 \mathrm{~km}$ long. For each individual section, we block average, compute the spatially lagged autocorrelation, and then average the individual correlation estimates. We restrict our correlation estimates to the range from 0 to $20 \mathrm{~km}$, because the uncertainty in the correlation increases rapidly (due to the decreasing number of realizations) for separations greater than $20 \mathrm{~km}$ (regardless of direction).

[22] The cross-shelf decorrelation length scales, estimated as the first zero crossing of the correlation function, are about $9 \mathrm{~km}$ for the raw and $7 \mathrm{~km}$ for the residual data. The decrease is caused by the persistent mean cross-shelf structure (Figure 6). The along-shelf decorrelation length scales are about $6 \mathrm{~km}$ for both the raw and residual data. The similar scales reflect the lack of a mean along-shelf structure. Residual field decorrelation length scales are nearly identical, suggesting an isotropic (in $x$ and $y$ ) eddy field superimposed on the mean cross-shelf structure.

[23] The decorrelation length scales are comparable to, but smaller than, the average internal deformation radius for the region of $12 \mathrm{~km}$ ( $\pm 1 \mathrm{~km}$ standard error), computed as

$$
L_{\mathrm{d}}=N H /|f|
$$

where $N$ is the depth-averaged buoyancy frequency, $H$ is the depth, and $f$ is the local Coriolis parameter. For comparison, there are two alternative length scales relevant to a dense eddy field on a sloping, continental shelf [Pringle, 2001]. One is the Rhines arrest scale

$$
L_{\mathrm{r}}=\sqrt{2 v / \beta_{\mathrm{t}}}, \quad \beta_{\mathrm{t}}=\frac{f}{H} \times \frac{\partial H}{\partial y},
$$

where $v$ is the RMS velocity of the eddy field and $\beta_{\mathrm{t}}$ is the topographic potential vorticity gradient. The second is a frictional scale based on the dissipation of kinetic energy by bottom friction

$$
L_{\mathrm{f}}=\frac{H}{r} v
$$

where $r$ is a linear friction coefficient $\left(4.5 \times 10^{-4} \mathrm{~m} \mathrm{~s}^{-1}\right)$. Using the average geostrophic velocity (Figure 8) for $v$, we compute average values for $L_{\mathrm{r}}$ and $L_{\mathrm{f}}$. The estimated decorrelation length scales (Figure 10) are significantly smaller than the average Rhines arrest scale of $20( \pm 4 \mathrm{~km})$ but similar to the frictional length scale of $9( \pm 2 \mathrm{~km})$.

\subsection{Temporal Variability}

[24] Inner shelf waters continue to cool and salinify over the 3 day survey period. This is evidenced by the tendency for increasingly cooler and saltier values in the extrema of the raw data (Figure 11). We estimate section averages for the eight gridded cross-shelf sections (from $y=6-38 \mathrm{~km}$ ),

$$
()_{\mathrm{av}}^{\mathrm{io}}=\frac{1}{A^{\mathrm{io}}} \int_{-H}^{0} \int_{y_{\mathrm{i}}}^{y_{\mathrm{o}}}() \mathrm{d} y \mathrm{~d} z
$$




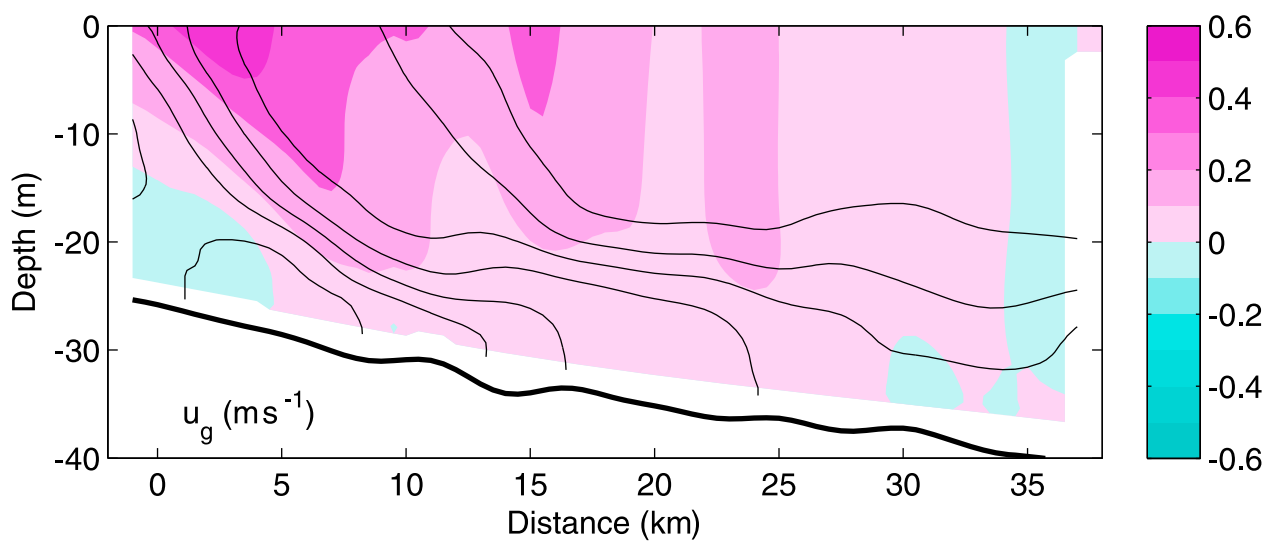

Figure 8. Along-shelf geostrophic currents, estimated from the average cross-shelf density section (Figure 6), smoothed over $2 \mathrm{~km}$ cross-shelf and $2 \mathrm{~m}$ vertical scales, and assuming zero velocity at the seafloor. Positive values indicate along-shelf, equatorward flow (toward the northwest).

where $y_{\mathrm{i}}$ and $y_{\mathrm{o}}$ are the inshore and offshore bounds of the section and $A$ is the total area of the cross-shelf section, and the integrals are evaluated using a trapezoidal numerical integration. Linear trends over time (Figure 11) fit to the section average data indicate that the local temperature change is $-0.2 \pm 0.1^{\circ} \mathrm{C} \mathrm{d}^{-1}(90 \%$ confidence limits $)$ and the local salinity change is $0.07 \pm 0.06 \mathrm{~d}^{-1}$. The associated temporal change in density is $0.1 \mathrm{~kg} \mathrm{~m}^{-3} \mathrm{~d}^{-1}$. Both the local rates of change of the section averages for temperature and salinity greatly exceed the cooling and salinification predicted by a

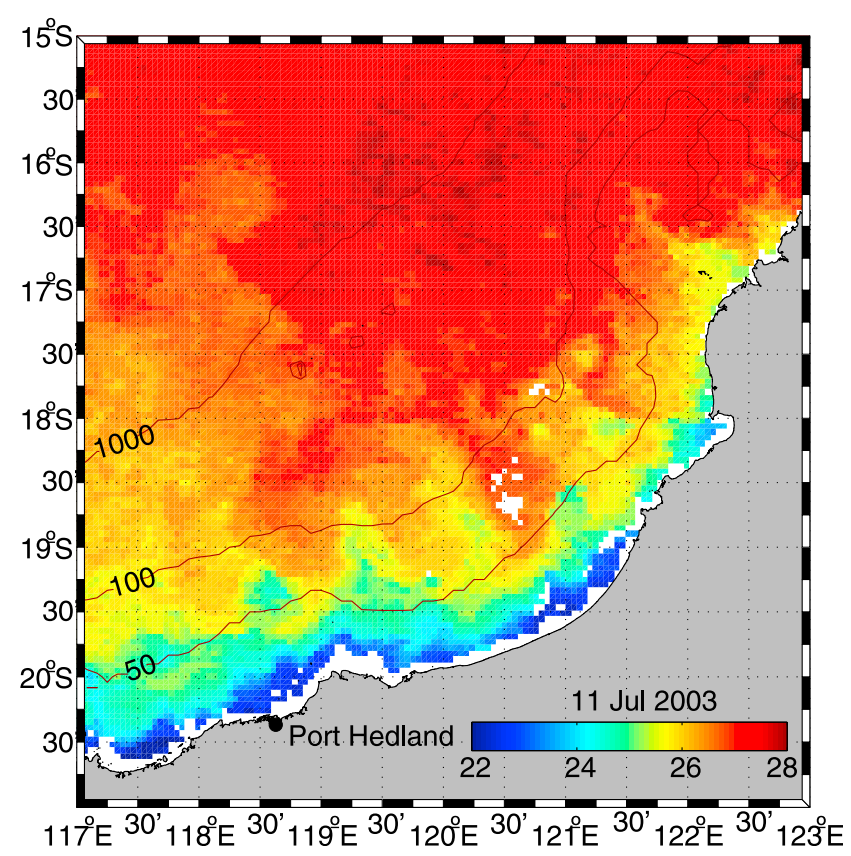

Figure 9. Daily composite satellite sea surface temperature image for 11 July 2003 from the Pathfinder Version 5.0 sea surface temperature data set, made available by National Oceanic and Atmospheric Administration/National Environmental Satellite, Data, and Information Service/National Oceanographic Data Center and the University of Miami [Kilpatrick et al., 2001]. one-dimensional balance with surface forcing (Figure 11, dashed lines),

$$
\begin{gathered}
\frac{\partial T_{\mathrm{av}}^{\mathrm{io}}}{\partial t}=\frac{Q}{\rho_{\mathrm{o}} c_{\mathrm{p}} H_{\mathrm{av}}^{\mathrm{io}}}, \\
\frac{\partial S_{a v}^{i o}}{\partial t}=\frac{E S_{\mathrm{o}}}{H_{a v}^{i o}},
\end{gathered}
$$

where $H_{\mathrm{av}}^{\text {io }}$ is the average bottom depth along the section. The implication then is that lateral fluxes must be responsible for the excess cooling and salinity increase.

[25] But the exact circumstance is not so simple; there is a distinct cross-shelf structure to the local rate of change of

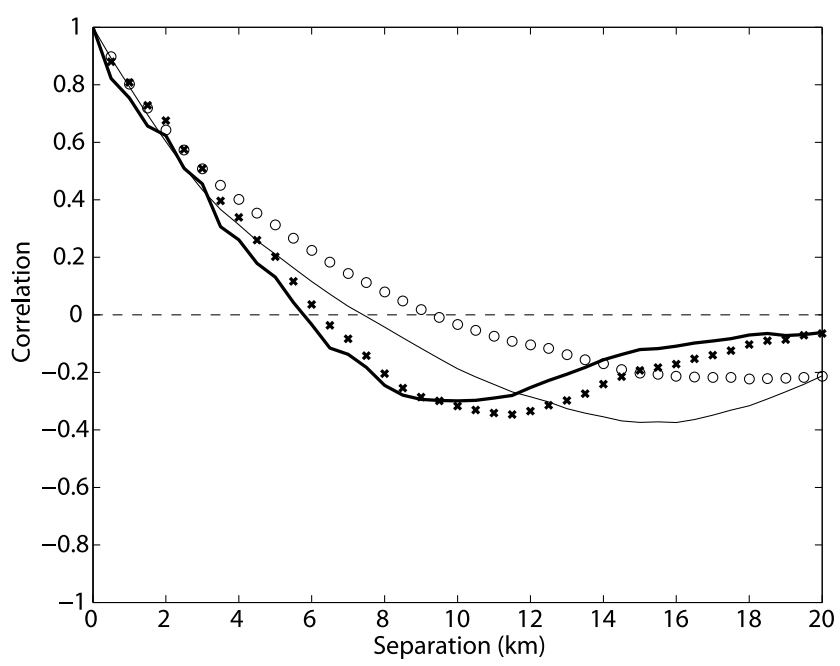

Figure 10. Along- and cross-shelf spatially lagged density autocorrelations estimated from the MiniBat observations at $10 \mathrm{~m}$ depth. The cross-shelf correlation structure is computed for the raw (open circles) and residual fields (thin line) after removing a quadratic background density field [e.g., Shearman et al., 1999]; likewise, the along-shelf correlation structure is computed for raw (crosses) and residual (thick line) fields. 

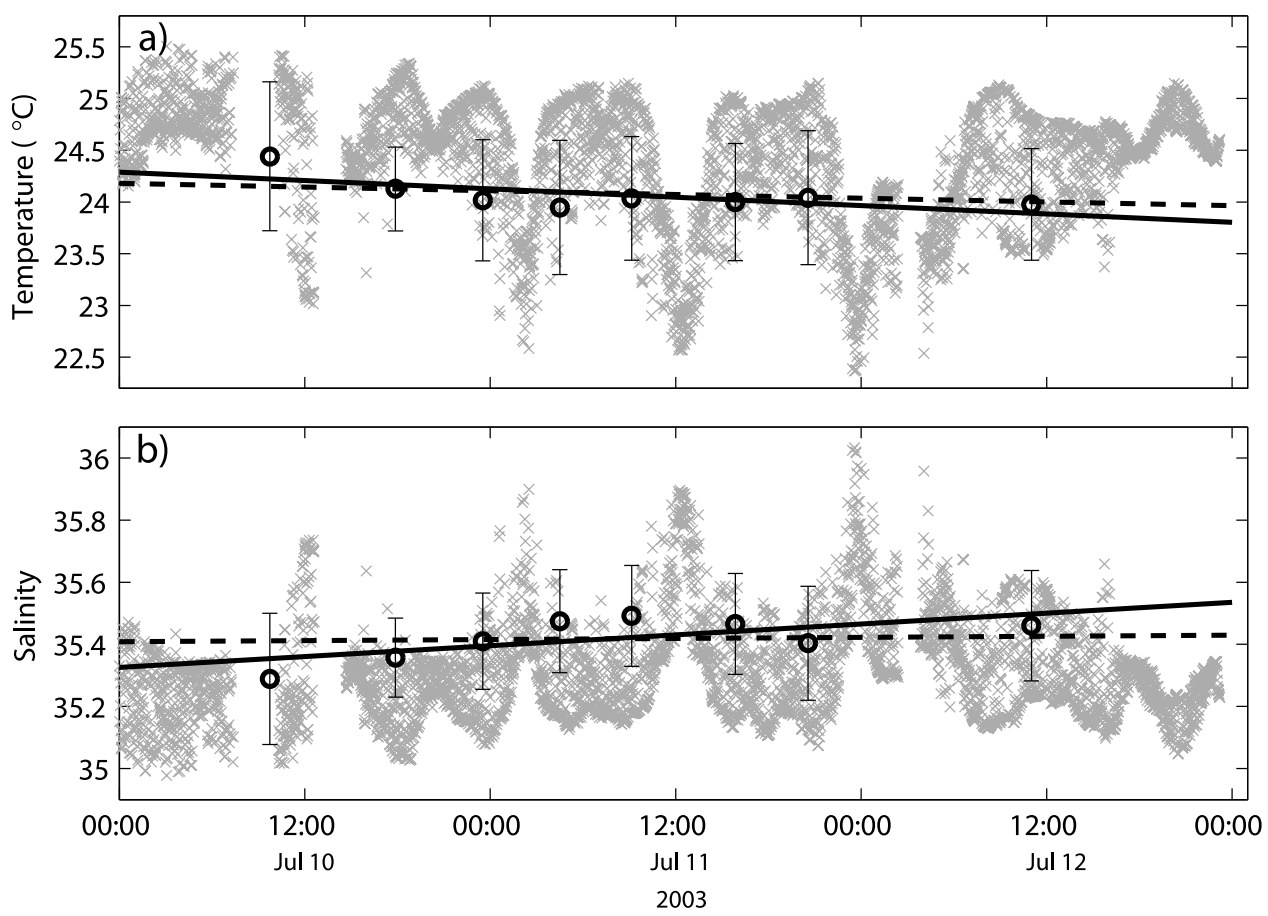

Figure 11. The time evolution of section-averaged (a) temperature and (b) salinity from the eight gridded cross-shelf sections of MiniBat data, spanning 6-38 km in the cross-shore direction. Section averages are shown by black circles with standard deviations. For reference, the raw MiniBat observations are shown (gray crosses). The local rate of change is represented by a line fit to the section averages (solid line) and is compared to the rate of change attributable to the surface forcing alone (dashed line).

temperature and salinity. The time- and depth-averaged cross-shelf structures of temperature and salinity reveal a region of strong, constant gradient from approximately 0 to $25 \mathrm{~km}$ offshore and a region of relatively constant (i.e., no gradient) temperature and salinity from 25 to $40 \mathrm{~km}$ offshore (Figures 12a and 12b). The local rate of change of both depthaveraged temperature and salinity (Figures $12 \mathrm{c}$ and $12 \mathrm{~d}$ ), estimated again by linear fit to the eight realizations, is effectively zero in the region of strong cross-shelf gradients $(0-25 \mathrm{~km})$ and strongly cooling $\left(-0.3{ }^{\circ} \mathrm{C} \mathrm{d}^{-1}\right.$ average $)$ and salinifying $\left(0.1 \mathrm{~d}^{-1}\right.$ average $)$ in the region of constant time-/ depth-averaged temperature and salinity $(25-40 \mathrm{~km})$. This structure is consistent with the notion of a steady state balance between surface fluxes and cross-shelf eddy transport of heat and salt (i.e. zero local change and strong cross-shelf gradient). The structure also suggests that the steady state balance does not exist over the entire shelf and that the cool salty water exported from the inshore region may cause the offshore region to cool and salinify more rapidly than can be explained by surface forcing alone (equation (9a) and equation (9b)).

\section{Discussion}

[26] The lack of agreement for a one-dimensional balance suggests that lateral transports must contribute to the heat and salt balances. Prior modeling efforts [Gawarkiewicz and Chapman, 1995; Chapman and Gawarkiewicz, 1997; Spall and Chapman, 1998; Pringle, 2001] have shown crossshelf transports to play an important role in balancing the surface loss of heat, freshwater, and hence buoyancy. In this case, the cross-shelf and depth-averaged heat and salt balances can be written as

$$
\begin{gathered}
\frac{\partial T_{\mathrm{av}}^{\mathrm{io}}}{\partial t}+\frac{F_{\mathrm{T}}^{\mathrm{o}}-F_{\mathrm{T}}^{\mathrm{i}}}{A^{\mathrm{io}}}=\frac{Q}{\rho_{\mathrm{o}} c_{\mathrm{p}} H_{\mathrm{av}}^{\mathrm{io}}}, \\
\frac{\partial S_{\mathrm{av}}^{\mathrm{io}}}{\partial t}+\frac{F_{\mathrm{S}}^{\mathrm{o}}-F_{\mathrm{S}}^{\mathrm{i}}}{A^{\mathrm{i}}}=\frac{E S_{\mathrm{o}}}{H_{\mathrm{av}}^{\mathrm{io}}},
\end{gathered}
$$

where $F_{\mathrm{T}}$ and $F_{\mathrm{S}}$ are the depth-integrated cross-shelf flux of temperature and salinity, respectively, at either end of the cross-shelf section $\left(y_{\mathrm{i}}, y_{\mathrm{o}}\right)$, indicated by the superscript. Likewise, the end points of section averages (e.g., $\left.T_{\mathrm{av}}^{\mathrm{io}}\right)$ are indicated by superscripts. The prior modeling studies of coastal polynyas and simple open-shelf domains undergoing cooling have demonstrated a balance between surface buoyancy loss and cross-shelf eddy flux after an initial adjustment period [Chapman and Gawarkiewicz, 1997; Spall and Chapman, 1998; Pringle, 2001]. In some cases, the resultant density field achieves a steady state [Chapman and Gawarkiewicz, 1997; Spall and Chapman, 1998] with zero local change in average density, and in other cases, the crossshelf density gradient is constant in time [Pringle, 2001] with a small but nonzero remnant local change in density. However, all of these studies find that transports are dominated by eddy fluxes and transports in the surface and bottom boundary layers are insignificant. Our observations unambiguously show that density is increasing offshore of the front during the 3 day sampling. Our observations though are ambiguous with regard to the cross-shelf transport mechanism; there is 

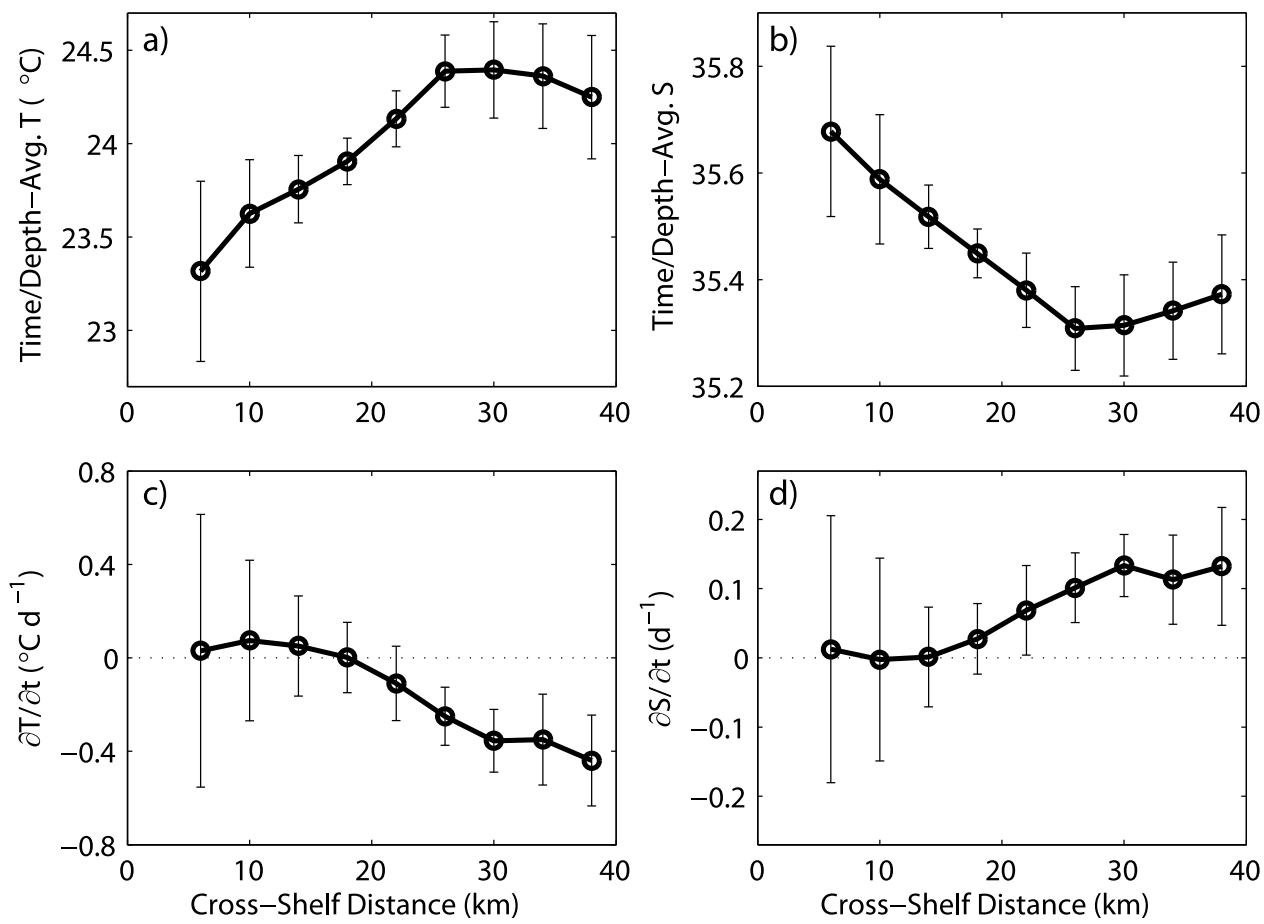

Figure 12. The depth-averaged (a) temperature and (b) salinity \pm one standard deviation versus crossshelf position, averaged from the eight gridded cross-shelf sections, and the local rate of change of depth-averaged (c) temperature and (d) salinity versus cross-shelf position, estimated by linear fit with $90 \%$ confidence intervals. The local rate of change for both temperature and salinity is effectively zero where there is a strong cross-shelf gradient in the mean field, and the local rate of change is significantly different from zero where there is no gradient in the mean field.

evidence of a homogeneous small-scale eddy field acting on a cross-shelf gradient (Figure 9) and evidence for transport in the bottom boundary layer as demonstrated by the salty tongues leaving at the shelf break [Brink and Shearman, 2006].

\subsection{Cross-Shelf Transport in the Boundary Layers}

[27] Up to this point, we have considered a simple balance argument in which the cross-shelf flux mechanism is general. Transport in the boundary layers or via eddy fluxes are natural possibilities to examine. If we assume that the cross-shelf flux is due to transport in the surface and bottom boundary layers, we can estimate $F_{\mathrm{T}}$ and $F_{\mathrm{S}}$ as

$$
\begin{aligned}
& F_{\mathrm{T}}=V_{\mathrm{b}}\left(T_{\mathrm{b}}-T_{\mathrm{s}}\right), \\
& F_{\mathrm{S}}=V_{\mathrm{b}}\left(S_{\mathrm{b}}-S_{\mathrm{s}}\right),
\end{aligned}
$$

where the subscripts $\mathrm{b}$ and $\mathrm{s}$ indicate the values in the bottom and surface boundary layers, respectively, and $V$ is volume transport, subject to the two-dimensional constraint of no depth-integrated cross-shelf flow

$$
\int_{-H}^{0} v \mathrm{~d} z=V_{\mathrm{b}}+V_{\mathrm{s}}=0 .
$$

[28] We can then separate the shelf into two regions (Figure 13) for which we have observations: the inshore portion from $y_{\mathrm{i}}=6 \mathrm{~km}$ to $y_{\mathrm{m}}=22 \mathrm{~km}$, with zero local change and strong cross-shelf gradients, and the offshore portion from $y_{\mathrm{m}}=22 \mathrm{~km}$ to $y_{\mathrm{o}}=38 \mathrm{~km}$, with strong local change and weak cross-shelf gradients (Figure 12). Estimating the terms in the heat and salt balances $(10 \mathrm{a}, \mathrm{b})$ for the inshore and offshore regions, as well as the entire section $\left(y_{\mathrm{i}}\right.$ to $\left.y_{\mathrm{o}}\right)$, we can solve for the three unknown cross-shelf bottom boundary layer transports: $V_{\mathrm{b}}^{\mathrm{i}}, V_{\mathrm{b}}^{\mathrm{m}}$, and $V_{\mathrm{b}}^{\mathrm{o}}$, where again superscripts denote cross-shelf position. Using the equations for the heat and salt budgets for the inshore region,

$$
\begin{gathered}
\frac{\left[T_{\mathrm{b}}^{\mathrm{m}}-T_{\mathrm{s}}^{\mathrm{m}}\right]}{A^{\mathrm{im}}} V_{\mathrm{b}}^{\mathrm{m}}-\frac{\left[T_{\mathrm{b}}^{\mathrm{i}}-T_{\mathrm{s}}^{\mathrm{i}}\right]}{A^{\mathrm{im}}} V_{\mathrm{b}}^{\mathrm{i}}=\frac{Q}{\rho_{\mathrm{o}} c_{\mathrm{p}} H_{\mathrm{av}}^{\mathrm{im}}}-\frac{\partial T_{\mathrm{av}}^{\mathrm{im}}}{\partial t}, \\
\frac{\left[S_{\mathrm{b}}^{\mathrm{m}}-S_{\mathrm{s}}^{\mathrm{m}}\right]}{A^{\mathrm{im}}} V_{\mathrm{b}}^{\mathrm{m}}-\frac{\left[S_{\mathrm{b}}^{\mathrm{i}}-S_{\mathrm{s}}^{\mathrm{i}}\right]}{A^{\mathrm{im}}} V_{\mathrm{b}}^{\mathrm{i}}=\frac{E S_{\mathrm{o}}}{H_{\mathrm{av}}^{\mathrm{im}}}-\frac{\partial S_{\mathrm{av}}^{\mathrm{im}}}{\partial t},
\end{gathered}
$$

the offshore region,

$$
\begin{gathered}
\frac{\left[T_{\mathrm{b}}^{\mathrm{o}}-T_{\mathrm{s}}^{\mathrm{o}}\right]}{A^{\mathrm{mo}}} V_{\mathrm{b}}^{\mathrm{o}}-\frac{\left[T_{\mathrm{b}}^{\mathrm{m}}-T_{\mathrm{s}}^{\mathrm{m}}\right]}{A^{\mathrm{mo}}} V_{\mathrm{b}}^{\mathrm{m}}=\frac{Q}{\rho_{\mathrm{o}} c_{\mathrm{p}} H_{\mathrm{av}}^{\mathrm{mo}}}-\frac{\partial T_{\mathrm{av}}^{\mathrm{mo}}}{\partial t}, \\
\frac{\left[S_{\mathrm{b}}^{\mathrm{o}}-S_{\mathrm{s}}^{\mathrm{o}}\right]}{A^{\mathrm{mo}}} V_{\mathrm{b}}^{\mathrm{o}}-\frac{\left[S_{\mathrm{b}}^{\mathrm{m}}-S_{\mathrm{s}}^{\mathrm{m}}\right]}{A^{\mathrm{mo}}} V_{\mathrm{b}}^{\mathrm{m}}=\frac{E S_{\mathrm{o}}}{H_{\mathrm{av}}^{\mathrm{mo}}}-\frac{\partial S_{\mathrm{av}}^{\mathrm{mo}}}{\partial t},
\end{gathered}
$$




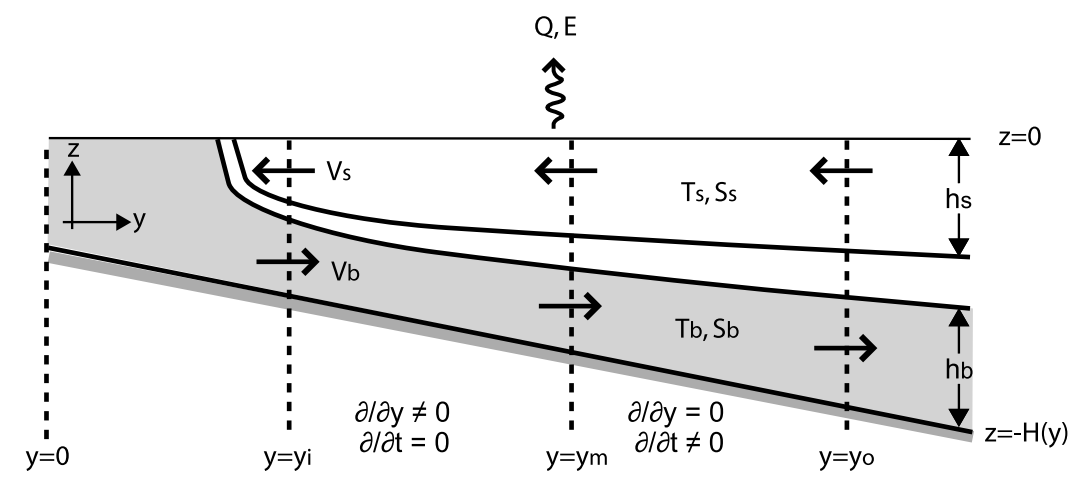

Figure 13. Schematic of the northwest Australian shelf and cross-shelf transport in the surface and bottom boundary layers.

and the entire section,

$$
\begin{aligned}
& \frac{\left[T_{\mathrm{b}}^{\mathrm{o}}-T_{\mathrm{s}}^{\mathrm{o}}\right]}{A^{\mathrm{io}}} V_{\mathrm{b}}^{\mathrm{o}}-\frac{\left[T_{\mathrm{b}}^{\mathrm{i}}-T_{\mathrm{s}}^{\mathrm{i}}\right]}{A^{\mathrm{io}}} V_{\mathrm{b}}^{\mathrm{i}}=\frac{Q}{\rho_{\mathrm{o}} c_{\mathrm{p}} H_{\mathrm{av}}^{\mathrm{io}}}-\frac{\partial T_{\mathrm{av}}^{\mathrm{io}}}{\partial t}, \\
& \frac{\left[S_{\mathrm{b}}^{\mathrm{o}}-S_{\mathrm{s}}^{\mathrm{o}}\right]}{A^{\mathrm{io}}} V_{\mathrm{b}}^{\mathrm{o}}-\frac{\left[S_{\mathrm{b}}^{\mathrm{i}}-S_{\mathrm{s}}^{\mathrm{i}}\right]}{A^{\mathrm{io}}} V_{\mathrm{b}}^{\mathrm{i}}=\frac{E S_{\mathrm{o}}}{H_{\mathrm{av}}^{\mathrm{io}}}-\frac{\partial S_{\mathrm{av}}^{\mathrm{io}}}{\partial t},
\end{aligned}
$$

where for the inshore region (equations (13a) and (13b)), $\partial T_{\mathrm{av}}^{\mathrm{im}} / \partial t=\partial S_{\mathrm{av}}^{\mathrm{im}} / \partial t=0$; for the offshore region (equations (13c) and (13d)), $\partial T_{\mathrm{av}}^{\mathrm{mo}} / \partial t=-0.3{ }^{\circ} \mathrm{C} \mathrm{d} \mathrm{d}^{-1}$ and $\partial S_{\mathrm{av}}^{\mathrm{mo}} / \partial t=0.1 \mathrm{~d}^{-1}$ (Figure 12); and for the entire section (equations (13e) and (13f)), $\partial T_{\mathrm{av}}^{\mathrm{io}} / \partial t=-0.2^{\circ} \mathrm{C} \mathrm{d} \mathrm{d}^{-1}$ and $\partial S_{\mathrm{av}}^{\mathrm{io}} / \partial t=0.07 \mathrm{~d}^{-1}$ (Figure 11), we solve for the three bottom boundary layer transports using linear least squares regression. The resulting transports are $V_{\mathrm{b}}^{\mathrm{i}}=0.3 \pm 2.6 \mathrm{~m}^{2} \mathrm{~s}^{-1}(90 \%$ confidence interval $)$, $V_{\mathrm{b}}^{\mathrm{m}}=0.5 \pm 2.6 \mathrm{~m}^{2} \mathrm{~s}^{-1}, V_{\mathrm{b}}^{\mathrm{o}}=-3.2 \pm 8.9 \mathrm{~m}^{2} \mathrm{~s}^{-1}$. Although the transport estimates have a high degree of uncertainty, they are consistent with the export of cold, salty water from the inshore region and accumulation of cold, salty water in the offshore region. The transport estimates for the inshore and middle locations are realistic in magnitude, while the offshore estimate is unrealistically large (the uncertainty is also large). The transport estimates can be divided by the average bottom boundary layer thickness at each location (Figure 7a) to estimate average cross-shelf currents in the bottom boundary layer of $0.03,0.04$, and $-0.17 \mathrm{~m} \mathrm{~s}^{-1}$ at $y_{\mathrm{i}}, y_{\mathrm{m}}$, and $y_{\mathrm{o}}$, respectively.

[29] For comparison, we can estimate the cross-shelf transport in the bottom Ekman layer

$$
V_{\mathrm{bE}}=\frac{\tau_{\mathrm{b}}^{\mathrm{x}}}{\rho_{\mathrm{a}} f},
$$

using the along-shelf geostrophic currents near the bottom (Figure 8) and a linear drag law

$$
\tau_{\mathrm{b}}^{\mathrm{x}}=r \rho_{\mathrm{o}} u_{\mathrm{b}}^{\mathrm{g}}
$$

[30] However, we have assumed zero along-shelf geostrophic flow at the seafloor, and while this is a useful assumption for calculating geostrophic currents, it is not a highly probable condition in reality. Offshore bottom Ekman transport requires poleward (negative) along-shelf, nearbottom geostrophic velocities. Therefore, we recompute the along-shelf geostrophic bottom currents required to match the estimates of cross-shelf transport in the bottom boundary layer,

$$
u_{\mathrm{b}}^{\mathrm{g}}=\frac{f V_{\mathrm{b}}}{r},
$$

and find at the inshore location $u_{\mathrm{b}}^{\mathrm{gi}}=-0.03 \mathrm{~m} \mathrm{~s}^{-1}$, at the middle location $u_{\mathrm{b}}^{\mathrm{gm}}=-0.06 \mathrm{~m} \mathrm{~s}^{-1}$, and at the offshore location $u_{\mathrm{b}}^{\mathrm{go}}=0.35 \mathrm{~m} \mathrm{~s}^{-1}$. The magnitude of the along-shelf geostrophic bottom current at the offshore location is unreasonably large (given the uncertainties in the transport estimate, this is not surprising); however, the values at the inshore and middle locations are quite realistic, requiring only relatively small changes to the geostrophic surface currents (Figure 8). These results also indicate a reversal in the vertical profile of along-shelf geostrophic flow with equatorward currents at the surface and poleward flow near the bottom over the inner region.

[31] Although there is a high degree of uncertainty, the bottom boundary layer transport estimates, at least at the inner and middle locations, describe conditions that are realistic in

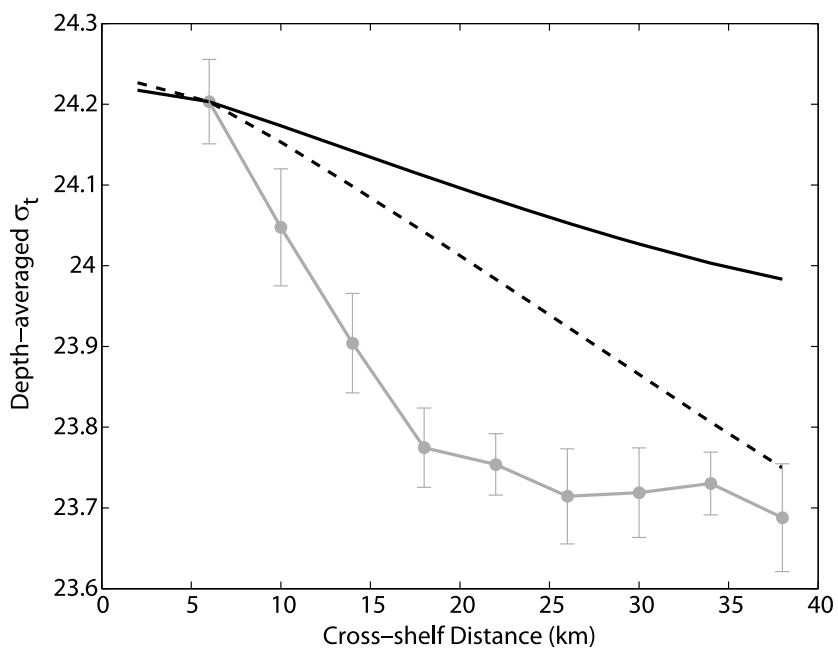

Figure 14. Depth-averaged cross-shelf density (gray) averaged over the duration of the survey from the eight cross-shelf sections and cross-shelf density structure estimated from the scaling argument (19a) with $L_{\mathrm{r}} / L_{\mathrm{f}}>1$ and assuming $F_{\mathrm{o}}=0$ (thick solid line) and $F_{\mathrm{o}}=F_{\mathrm{B}}^{\mathrm{m}}$ (dashed line). 
magnitude and direction and consistent with a steady state inner region and a cooling, salinifying outer region. Furthermore, the near-bottom along-shelf geostrophic flows required to drive a matching bottom Ekman transport are reasonable values, compared to the geostrophic estimates from the density field and an assumed zero flow at the bottom. While only suggestive, these results support the idea that the bottom boundary layer is at least a possible mechanism for exporting cold, salty, dense water from a shelf undergoing large heat and freshwater surface fluxes.

[32] The boundary layer transport estimates do not identify a mechanism to drive the balancing return flow in the surface layer. Winds are relatively weak and so are unlikely to be able to drive a balancing surface Ekman transport. A positive along-shelf pressure gradient would drive a potentially balancing onshore geostrophic flow. In this case, the pressure gradient must equal $-f V_{\mathrm{b}}=2.5 \times 10^{-5} \mathrm{~m}^{2} \mathrm{~s}^{-2}$, which is comparable in magnitude to estimates of along-shelf pressure gradients driving the LC system [Ridgway and Condie, 2004]. Finally, if the more realistic cross-shelf transport estimates at the inshore and middle locations are consistent along the $700 \mathrm{~km}$ of northwest Australian coastline exhibiting cool water nearshore as in the satellite SST (Figure 9), then this would lead to a volume export of $0.4 \mathrm{~Sv}$. In our model, this volume transport is balanced by an overlying return flow; however, the offshore transport would represent a sizable export of any material in the bottom boundary layer, such as suspended sediments.

\subsection{Cross-Shelf Transport by Eddies}

[33] Cross-shelf transports by eddies have been shown in previous laboratory and modeling studies to be the dominant buoyancy flux mechanism balancing surface fluxes in coastal polynyas and continental shelf domains [Gawarkiewicz and Chapman, 1995; Chapman and Gawarkiewicz, 1997; Spall and Chapman, 1998; Pringle, 2001]. Using the average cross-shelf transports we estimated from the heat and salt budgets, we can compute the commensurate depth-integrated cross-shelf buoyancy fluxes,

$$
F_{\mathrm{B}}=-V_{\mathrm{b}} \frac{g}{\rho_{\mathrm{o}}}\left(\rho_{\mathrm{b}}-\rho_{\mathrm{s}}\right),
$$

finding that $F_{\mathrm{B}}^{\mathrm{i}}=-1.9 \times 10^{-3} \mathrm{~m}^{3} \mathrm{~s}^{-3}, F_{\mathrm{B}}^{\mathrm{m}}=-3.1 \times 10^{-3} \mathrm{~m}^{3} \mathrm{~s}^{-3}$, and $F_{\mathrm{B}}^{\mathrm{o}}=7.2 \times 10^{-3} \mathrm{~m}^{3} \mathrm{~s}^{-3}$. Following Spall and Chapman [1998], the depth-integrated cross-front eddy buoyancy (density) flux can be parameterized,

$$
H \overline{v^{\prime} \rho^{\prime}}=c_{\mathrm{e}} v_{\mathrm{m}} \Delta \rho H
$$

where $\Delta \rho$ is the density change across the front, $v_{\mathrm{m}}$ is the maximum along-front velocity, and $c_{\mathrm{e}}$ is the efficiency parameter. Spall and Chapman [1998] found $c_{\mathrm{e}} \approx 0.045$, consistent with previous results. Using values of $v_{\mathrm{m}}=0.48 \mathrm{~m}$ $\mathrm{s}^{-1}$ and $\Delta \rho=0.6 \mathrm{~kg} \mathrm{~m}^{-3}$ from our observations on the northwest Australian shelf, we estimate the cross-frontal density flux due to eddies as $0.4 \mathrm{~kg} \mathrm{~s}^{-1} \mathrm{~m}^{-1}$ with a corresponding buoyancy $\left(-g \rho / \rho_{\mathrm{o}}\right)$ flux of $-3.7 \times 10^{-3} \mathrm{~m}^{3} \mathrm{~s}^{-3}$, similar to our estimates for $F_{\mathrm{B}}^{\mathrm{i}}$ and $F_{\mathrm{B}}^{\mathrm{m}}$, the fluxes over the inshore region with strong cross-shelf gradients and an apparent steady state balance (Figure 12), suggesting that eddy fluxes are capable of providing the cross-shelf transport required to balance the heat and salt equations (10a, 10b), much like the previous modeling work [Gawarkiewicz and Chapman, 1995; Chapman and Gawarkiewicz, 1997; Spall and Chapman, 1998].

[34] Pringle [2001] examines cross-shelf eddy flux using a primitive equation model of an along-shelf uniform channel with sloping bottom and linear bottom friction undergoing a constant surface buoyancy loss. In the model, a front forms and becomes unstable, developing a complex eddy field. Eventually the model achieves a steady state cross-shelf density gradient; however, the density may continue to increase with time, because the cross-shelf flux obtained by the eddies acting on the constant background density field may not entirely balance the surface flux. Pringle [2001] found close agreement between the modeled cross-shelf density structure and a scaling argument determined by

$$
\begin{aligned}
& \overline{\frac{\partial \rho}{\partial y}}=\left\{\begin{array}{cc}
\frac{r^{\frac{1}{3}} \rho_{\mathrm{o}}^{\frac{2}{3}} f^{\frac{2}{3}} F^{\frac{1}{3}}}{\gamma^{\frac{1}{3}} H^{\frac{4}{3}} g^{\frac{2}{3}}} & L_{\mathrm{r}} / L_{\mathrm{f}} \geq 1 \\
\frac{\partial H^{\frac{1}{5}}}{\partial y} \frac{\rho_{\mathrm{o}}^{\frac{3}{5}} f^{\frac{4}{5}} F^{\frac{2}{5}}}{2^{\frac{1}{5}} \gamma^{\frac{2}{5}} H^{\frac{6}{5}} g^{\frac{3}{5}}} & L_{\mathrm{r}} / L_{\mathrm{f}} \leq 1
\end{array}\right. \\
& F=\int_{0}^{y} \frac{g B}{\rho_{\mathrm{o}}} \mathrm{d} y-\frac{\partial \bar{\rho}}{\partial t} \int_{0}^{y} H \mathrm{~d} y, \\
& \frac{\partial \bar{\rho}}{\partial t}=\left(\int_{0}^{y} \frac{g B}{\rho_{\mathrm{o}}} \mathrm{d} y-F_{\mathrm{o}}\right)\left(\int_{0}^{y} H \mathrm{~d} y\right)^{-1}
\end{aligned}
$$

where $\gamma=0.3-0.5$ is the correlation between the density field and cross-shelf velocity field (estimated from the model) and $F_{\mathrm{o}}$ is the unknown cross-shelf flux at the offshore boundary, which Pringle [2001] examines in "open" (where $F_{\mathrm{o}}$ equals the cross-shelf integral of the surface flux and the density field is in a steady state) and "closed" (where $F_{\mathrm{o}}=0$ and the density over the shelf continues to increase) configurations. Using our measurements of the surface buoyancy flux, we compute the cross-shelf density structure by integrating (19a), recognizing that $L_{\mathrm{r}} / L_{\mathrm{f}}>1$ for the northwest Australian shelf. The scaling argument with $F_{\mathrm{o}}=0$ under predicts the cross-shelf density gradient (Figure 13, solid line) and predicts a continued increase in average density of $0.024 \mathrm{~kg} \mathrm{~m}^{-3}$ $\mathrm{d}^{-1}$, compared to the observed increase of $0.1 \mathrm{~kg} \mathrm{~m}^{-3} \mathrm{~d}^{-1}$ (Figure 11). However, if we use the estimate of cross-shelf flux from through the bottom boundary layer at the middle location to specify $F_{\mathrm{o}}=F_{\mathrm{B}}^{\mathrm{m}}$, we get an improved agreement in the cross-shelf structure (Figure 13, dashed line). Furthermore, the local change in average density switches sign and is reduced two orders of magnitude to $-4.5 \times 10^{-4} \mathrm{~kg} \mathrm{~m}^{-3} \mathrm{~d}^{-1}$, suggesting a practical steady state for both the cross-shelf density gradient and density field. In addition, the cross-shelf structure of the inshore region is more comparable to the scaling estimates with $F_{\mathrm{o}}=F_{\mathrm{B}}^{\mathrm{m}}$, while the weaker cross-shelf gradient in the offshore region is more comparable to the scaling with $F_{\mathrm{o}}=0$. The similarities between the observed cross-shelf density structure and scaling estimates of Pringle 
[2001] reinforce the idea that cross-shelf flux is achieved predominantly by eddies.

\section{Conclusion}

[35] Observations from the northwest Australian shelf during June/July 2003 reveal large outgoing surface fluxes of heat and freshwater and continental shelf waters that are increasingly cool, salty, and dense onshore. There is a strong front at the $25 \mathrm{~m}$ isobath with peak along-shelf geostrophic currents of $0.48 \mathrm{~m} \mathrm{~s}^{-1}$. The front is identifiable along the entire northwest Australian shelf, exhibiting complex filamentary and eddy-like structures. Inshore of the front, hydrographic conditions are well mixed, and offshore of the front, the vertical structure is characterized by a two-layer system: a surface layer that shares characteristics with the far offshore surface mixed layer and a bottom layer that connects the cool, salty water inshore of the front to the mid and outer shelf.

[36] Over time, shelf waters are decreasing in temperature and increasing in salinity; however, local rates of change do not agree with a one-dimensional balance with surface fluxes. The shelf separates into two regions: the inshore region with strong cross-shelf gradients of temperature and salinity and no significant local rates of change, and the offshore region with no cross-shelf gradients but strong local rates of change for both temperature and salinity. Assuming two-dimensional heat and salt balances, we find that the cross-shelf fluxes consistent with this two region structures can be achieved by either the expected eddy transports or by transport in the boundary layers.

[37] Reasonable cross-shelf transports in the bottom boundary layer of about $0.5 \mathrm{~m}^{2} \mathrm{~s}^{-1}$ are inferred from the mean heat and salt budgets for a two-dimensional cross-shelf section and are consistent in magnitude and direction to bottom Ekman transports driven by a slightly baroclinic along-shelf flow with equatorward flow at the surface and poleward flow near the bottom. There is a great deal of uncertainty in these transport estimates due to the limited extent of the observations, a strong argument for continued observational studies of dense water formation. The cross-shelf buoyancy flux estimates from the heat and salt balances are comparable to estimates of cross-shelf eddy driven fluxes, the dominant mechanism for cross-shelf transport in models of dense water formation [Gawarkiewicz and Chapman, 1995; Chapman and Gawarkiewicz, 1997; Spall and Chapman, 1998], and there is good agreement between the observed cross-shelf density structure and the structure predicted from a scaling argument based on cross-shelf eddy fluxes [Pringle, 2001], particularly when the offshore boundary fluxes match the estimates from the observed heat and salt balances.

[38] Our limited observations on the northwest Australian shelf cannot definitively determine whether cross-shelf transport is achieved by eddies or via the boundary layers or through some combination of both. However, the problem in general is tractable, and the northwest Australian shelf is an ideal location to study it. What we lack primarily are direct velocity observations and a sufficient quantity of observations to constrain our cross-shelf flux estimates (specifically the boundary layer transports and the eddy fluxes). The needed observations might be a few months of moored observations of the velocity field in conjunction with the temperature, salinity, and surface forcing fields. Simply being able to compute (rather than infer) cross-shelf fluxes directly will be a major step forward. It would also be useful to estimate the alongshore flux divergence to understand to what extent the heat and salt budgets are two dimensional. This could be done by adding a second mooring displaced along shore or by repeated ship-based surveys that can detect any mean alongshore gradients. In any case, intensive shipbased measurements would be able to describe fully the eddy features that play such an ambiguous role in the present observations.

[39] Acknowledgments. We thank Frank Bahr, Tracy Engstrom, Sarah Searson, Heidi Baird, Leon Majewski, Mary Lardie, Peter Winsor, Brandon Wasnewski, Steve Foley, Craig Marquette, Frank Bahr, Robyn Conmy, Greta Klungness, and especially the Master and crew of the R/V Melville. The Office of Naval Research funded this effort (grant N00014-00-10767).

\section{References}

Aagaard, K., L. K. Coachman, and E. Carmack (1981), On the halocline of the Arctic Ocean, Deep-Sea Res. A, 28, 529-545.

Antonov, J. I., R. A. Locarnini, T. P. Boyer, A. V. Mishonov, and H. E. Garcia (2006), World Ocean Atlas 2005, Volume 2: Salinity, in NOAA Atlas NESDIS 62, edited by S. Levitus, p. 182, U.S. Government Printing Office, Washington, D. C.

Brink, K. H., and R. K. Shearman (2006), Bottom boundary layer flow and salt injection from the continental shelf to slope, Geophys. Res. Lett., 33, L13608, doi:10.1029/2006GL026311.

Brink, K. H., F. Bahr, and R. K. Shearman (2007), Alongshore currents and mesoscale variability near the shelf edge off northwestern Australia, J. Geophys. Res., 112, C05013, doi:10.1029/2006JC003725.

Cavalieri, D. J., and S. Martin (1994), The contribution of Alaskan, Siberian, and Canadian coastal polynyas to the cold halocline layer of the Arctic Ocean, J. Geophys. Res., 99, 18,343-18,362.

Cenedese, C., J. A. Whitehead, T. A. Ascarelli, and M. Ohiwa (2004), A dense current flowing down a sloping bottom in a rotating fluid, J. Phys. Oceanogr., 34, 188-203.

Chapman, D. C., and G. Gawarkiewicz (1997), Shallow convection and buoyancy equilibration in an idealized coastal polynya, J. Phys. Oceanogr., 27, 555-566.

Condie, S. A. (1995), Descent of dense water masses along continental slopes, J. Mar. Res., 53, 897-928.

Dale, A. C., J. A. Barth, M. D. Levine, and J. A. Austin (2008), Observations of mixed layer restratification by onshore surface transport following wind reversal in a coastal upwelling region, J. Geophys. Res., 113, C01010, doi:10.1029/2007JC004128.

Daley, R. (1993), Atmospheric Data Analysis, Cambridge Univ. Press, New York.

Fairall, C., E. Bradley, D. Rogers, J. Edson, and G. Young (1996), Bulk parameterization of air-sea fluxes for Tropical Ocean-Global Atmosphere Coupled-Ocean Atmosphere Response Experiment, J. Geophys. Res., 101, 3747-3764, doi:10.1029/95JC03205.

Gawarkiewicz, G., and D. C. Chapman (1995), A numerical study of dense water formation and transport on a shallow, sloping continental shelf, J. Geophys. Res., 100, doi:10.1029/94JC01742.

Gentilli, J. (1972), Thermal anomalies in the eastern Indian Ocean, Nature (London), Phys. Sci., 238, 93-95.

Godfrey, J. S., and J. V. Mansbridge (2000), Ekman transports, tidal mixing, and the control of temperature structure in Australia's northwest waters, J. Geophys. Res., 105(C10), 24021-24044, doi:10.1029/ 2000JC900104.

Godfrey, J. S., and K. R. Ridgway (1985), The large-scale environment of the poleward-flowing Leeuwin Current, Western Australia: Longshore steric height gradients, wind stresses and geostrophic flow, J. Phys. Oceanogr., 15, 481-495.

Holloway, P. E. (1983a), Internal tides on the Australian north-west shelf: A preliminary investigation, J. Phys. Oceanogr., 13, 1357-1370.

Holloway, P. E. (1983b), Tides on the Australian north west shelf, Aust. J. Mar. Freshwater Res., 34, 213-230.

Holloway, P. E. (1994), Observations of internal tide propagation on the Australian north west shelf, J. Phys. Oceanogr., 24, 1706-1716. 
Holloway, P. E. (1995), Leeuwin current observations on the Australian north west shelf, May-June 1993, Deep-Sea Res. I, 42, 285, doi:10.1016/0967-0637(95)00004-P.

Holloway, P. E., and H. C. Nye (1985), Leeuwin Current and wind distributions on the southern part of the Australian north west shelf between January 1982 and July 1983, Aust. J. Mar. Freshwater Res., 36, 123-137.

Holloway, P. E., P. G. Chatwin, and P. Craig (2001), Internal tide observations from the Australian north west shelf in summer 1995, J. Phys. Oceanogr., 31, 1182-1199.

Huthnance, J. M. (1995), Circulation, exchange and water masses at the ocean margin: the role of physical processes at the shelf edge, Prog. Oceanogr., 35, 353 .

Kilpatrick, K. A., G. P. Podesta, and R. Evans (2001), Overview of the NOAA/NASA advanced very high resolution radiometer Pathfinder algorithm for sea surface temperature and associated matchup database, J. Geophys. Res., 106, 9179-9197, doi:10.1029/1999JC000065.

Lentz, S. J. (1992), The surface boundary layer in coastal upwelling regions, J. Phys. Oceanogr., 22, 1517-1539.

Lentz, S. J., and J. H. Trowbridge (1991), The bottom boundary layer over the northern California shelf, J. Phys. Oceanogr., 21, 1186-1201.

Locarnini, R. A., A. V. Mishonov, J. I. Antonov, T. P. Boyer, and H. E. Garcia (2006), World Ocean Atlas 2005, Volume 1: Temperature, in NOAA Atlas NESDIS 61, edited by S. Levitus, p. 182, U.S. Government Printing Office, Washington, D. C.

Lueck, R. G. (1990), Thermal inertia of conductivity cells: Theory, J. Atmos. Oceanic Tech., 7, 741-755.

Mountain, D. G., G. A. Strout, and R. C. Beardsley (1996), Surface heat flux in the Gulf of Maine, Deep-Sea Res. II, 43, 1533.
Pringle, J. M. (2001), Cross-shelf eddy heat transport in a wind-free coastal ocean undergoing winter time cooling, J. Geophys. Res., 106, doi:10.1029/2000JC900148.

Ridgway, K. R., and S. A. Condie (2004), The 5500-km-long boundary flow off western and southern Australia, J. Geophys. Res., 109, C04017, doi:10.1029/2003JC001921

Shearman, R. K., J. A. Barth, and P. M. Kosro (1999), Diagnosis of the three-dimensional circulation associated with mesoscale motion in the California current, J. Phys. Oceanogr., 29, 651-670.

Spall, M. A., and D. C. Chapman (1998), On the efficiency of baroclinic eddy heat transport across narrow fronts, J. Phys. Oceanogr., 28, 2275-2287.

Strub, P. T., P. M. Kosro, A. Huyer, and C. T. Z. Collaborators (1991), The nature of the cold filaments in the California current system, J. Geophys. Res., 96, 14,743-14,768.

Whitehead, J. A., M. E. Stern, G. R. Flierl, and B. A. Klinger (1990), Experimental observations of baroclinic eddies on a sloping bottom J. Geophys. Res., 95, doi:10.1029/JC095iC06p09585.

Wyrtki, K. (1962), The upwelling in the region between Java and Australia during the southeast monsoon, Aust. J. Mar. Freshwater Res., 13, $217-225$

K. H. Brink, Department of Physical Oceanography, Woods Hole Oceanographic Institution, MS \#21, Clark 301, Woods Hole, MA 02543 , USA.

R. K. Shearman, College of Oceanic and Atmospheric Sciences, Oregon State University, 104 COAS Administration Building, Corvallis, OR 97331, USA. (shearman@coas.oregonstate.edu) 